\title{
Energy and the Protection of the Atmosphere
}

Nebojša Nakićenović

Arnulf Grübler

RR-00-18

August 2000

Reprinted from the International Journal of Global Energy Issues, 13(1-3):4-57, 2000. 
Research Reports, which record research conducted at IIASA, are independently reviewed before publication. Views or opinions expressed herein do not necessarily represent those of the Institute, its National Member Organizations, or other organizations supporting the work.

Reprinted from the International Journal of Global Energy Issues, 13(1-3):4-57, 2000.

Copyright (c) 2000 with permission from Inderscience Enterprises Ltd.

For more information visit our web site: www. inderscience.com

All rights reserved. No part of this publication may be reproduced or transmitted in any form or by any means, electronic or mechanical, including photocopy, recording, or any information storage or retrieval system, without permission in writing from the copyright holder. 


\title{
Energy and the protection of the atmosphere
}

\section{Nebojsa Nakicenovic and Arnulf Grübler}

\author{
Environmentally Compatible Energy Strategies Project, International \\ Institute for Applied Systems Analysis, A-2361 Laxenburg, Austria \\ Fax: (+43-2236) 71313.
}

\begin{abstract}
The essay reviews major environmental problems of energy development within a broader development and sustainability context. The role of energy in human development and major historical trends as well as their implications for carbon dioxide emissions are discussed. After summarizing the scientific understanding of current and possible future climate change the paper reviews available mitigation and adaptation options including: energy efficiency improvements, fuels switching, zero-carbon energy options, emission abatement and disposal at large point sources, enhancement of natural sinks, and adaptation measures. Specific circumstances of developing versus industrialized countries are outlined. The essay concludes with a review of policy instruments that could reconcile protection of the atmosphere with human development and sustainability objectives.
\end{abstract}

Keywords: Energy; carbon dioxide; climate change; historical trends; mitigation options; policy instruments.

Reference to this paper should be made as follows: Nakicenovic, N. and Grübler, A. (2000) 'Energy and the protection of the atmosphere', Int. J. Global Energy Issues, Vol. 13, Nos. 1-3, pp.4-57.

Biographical notes: Nebojsa Nakicenovic is Project Leader of the Environmentally Compatible Energy Strategies Project at the International Institute for Applied Systems Analysis (IIASA), Laxenburg, Austria. He also serves as Convening Lead and Lead Author for the Intergovernmental Panel on Climate Change (IPCC) and as guest professor at the Technical University of Graz. Prof. Nakicenovic holds bachelor's and master's degrees in economics and computer science from Princeton University, New Jersey, USA and the University of Vienna, where he also completed his Ph.D.

Arnulf Grübler is a research scholar at IIASA, Laxenburg, Austria and Lead Author for the IPCC. He holds masters and PhDs degrees from the Technical University in Vienna, Austria and is lecturer at the Mining University, Leoben, Austria. He is editorial board member of Technological Forecasting \& Social Change and Journal of Industrial Ecology. His recent publications include Technology and Global Change, published by Cambridge University Press.

\section{Introduction}

The earth's atmosphere is affected by many interrelated anthropogenic sources of interference that can lead to environmental impacts and ultimately to irreversible changes in the climate system. Human interferences include local and regional air pollution and increasing concentrations of greenhouse gases, aerosols and halocarbons. Combustion of 
fossil fuels and unsustainable uses of biomass fuels cause extensive local and regional (transboundary) air pollution often resulting in acidification that damages entire ecosystems. The extraction, conversion and combustion of fossil fuels, and to a lesser degree land-use changes and agriculture, lead to increasing concentrations of greenhouse gases that are altering the radiative balance of the atmosphere, possibly causing climate change. Human activities have increased the atmospheric concentration of many naturally occurring gases and have also added new ones. Anthropogenic sources of chlorofluorocarbons are adding to the greenhouse effect and are gradually destroying the ozone layer. Taken together, these human activities are projected to change regional and global climate. These changes will affect large populations and especially those communities that are most vulnerable, particularly the poor who have lower abilities and resources to adapt to changing climatic conditions.

Protection of the atmosphere is one of the important preconditions for ensuring that economic development can proceed in a sustainable manner. This essay addresses issues related to the protection of the atmosphere from energy-related pollution sources. It analyses the relationship between energy and development, prevailing trends in energy use throughout the world and possible future developments. Possible impacts on the atmosphere, and strategies for mitigating and avoiding adverse impacts of possible climate change are discussed. The report concludes with an assessment of the available policy measures for the protection of the atmosphere within the context of sustainable human development.

\subsection{Local and transboundary air pollution}

Local and transboundary pollutants from energy-related activities cause the deterioration of air quality in many urban and some rural regions throughout the world [1,2]. Various forms of pollution often result in respiratory diseases and other health impacts and hazards. They also result in economic damage and endanger ecosystems.

High levels of indoor air pollution from burning low quality biomass or coal in traditional open fireplaces are widespread in developing countries [3]. This is harming the health of women and children in particular. Sulphur and particulate concentrations that are associated largely with coal combustion far exceed the World Health Organization standards in numerous large urban agglomerations, especially in developing countries [2].

Sulphur dioxide and nitrogen oxides emissions from fossil power plants and dense motorized traffic cause regional and transboundary air pollution that leads to acidification of forests, lakes and soils. 'Acid rain' has been a particular problem in Europe and North America. More recently, transboundary air pollution and increasing acidification have also become sources of concern in the rapidly developing, coal-intensive economies of East Asia [4].

\subsection{Increasing concentrations of greenhouse gases}

Concentrations of greenhouse gases have increased significantly since the beginning of the fossil fuel era two centuries ago. Atmospheric concentrations of carbon dioxide have increased by $30 \%$ (Figure 1), those of methane by $150 \%$ and those of nitrous oxides by over $10 \%$. Scientific evidence is strong that most of these increases are due to human 
activities such as the burning of fossil fuels, land-use changes and agriculture. It will take many decades to centuries before additional atmospheric concentrations of greenhouse gases related to human activities are absorbed by natural sinks. Increasing concentrations of greenhouse gases tend to warm the atmosphere, whereas aerosols such as sulphur dioxide tend to cool it in some regions.

Figure 1 Changes in atmospheric carbon dioxide concentration as measured at Mauna Loa Observatory, Hawaii (in parts per million by volume, ppmv)

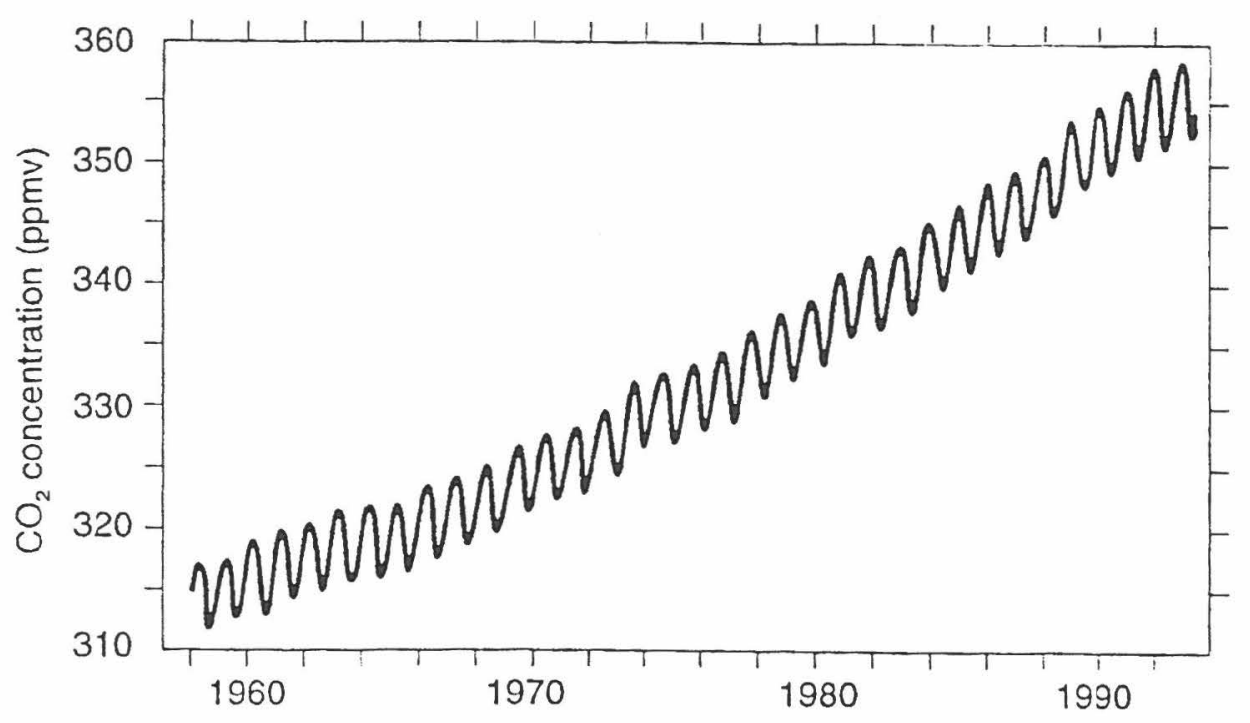

Source: Bolin, [5]

These increases in the atmospheric greenhouse gases and aerosols, taken together, are expected to lead to higher mean global temperatures and are projected to change regional and global climates including inter alia precipitation, soil moisture, air and ocean currents and sea levels [6]. Climate change, in turn, could lead to adverse environmental impacts affecting human activities and endangering sustainable development. The exact nature of these impacts, including their extent, variability and regional patterns, are subject to considerable scientific uncertainty. The climate system is by its nature difficult to predict. Therefore, future climate changes may also involve 'surprises' [6]. Many ecosystems, some agricultural activities, and low-lying coastal areas are particularly vulnerable to projected climate change even in the absence of surprises. Poor populations are highly vulnerable, primarily because they lack sufficient resources to protect themselves from adverse impacts, such as extreme weather conditions and to adapt to climate changes.

The depletion of the stratospheric ozone layer is largely caused by emissions of chlorofluorocarbons and halons. This results in increased ultraviolet radiation reaching the earth's surface that can impact on human health, including increased cases of skin cancer and eye disease. The chlorofluorocarbons also produce a greenhouse effect: however, this is offset somewhat by decreases in ozone which is also a greenhouse gas. A 
reduction of the ozone depleting substances is regulated by the Montreal Protocol [7], but some of the replacements for ozone depleting substances are, in turn, potent greenhouse gases.

\subsection{Energy for development and climate change}

Energy production and use is the main source of many of the threats to the earth's atmosphere. Despite tremendous increases in commercial energy use to date, the majority of the global population still has inadequate access to the kind of energy services enjoyed by the inhabitants of the industrialized countries. More than two billion people have no access to modern energy services whatsoever [8]. A lack of adequate energy services is one of the unfortunate symptoms of poverty. The inequalities are so great that it would be virtually impossible for the majority of the world's population to enjoy similar resource intensive energy-use patterns as those prevailing in industrialized countries. The assimilative capacity of the biosphere to absorb gigantic releases of pollutants would be far exceeded; although science is at present not in a position to suggest particular threshold levels or exact boundary conditions for future energy development.

More sustainable energy patterns throughout the world and the protection of the atmosphere are therefore recognized as important policy objectives at both national and international levels [1]. International environmental agreements are being extended from the local and national to international levels. Examples include the European Convention on Long-Range Transboundary Air Pollution [9] and its 1995 Second Sulphur Protocol, the Montreal Protocol [7] for the reduction of chlorofluorocarbon emissions, and the United Nations Framework Convention on Climate Change (FCCC) whose ultimate objective is the "stabilization of greenhouse gas concentrations in the atmosphere at a level that would prevent dangerous anthropogenic interference with the climate system" [10].

Adequate protection of the earth's atmosphere to prevent 'dangerous' interference involves a number of formidable challenges. Considerable energy increases are required to satisfy basic human needs and to further social and economic development. However, the current, largely inadequate, use of energy in many instances already produces emissions that exceed tolerable levels in urban regions and that exceed critical loads for many ecosystems in rural regions. Remedies are needed urgently, but the current dependence on fossil fuels for the provision of energy services will persist for many decades to come. Again, the adverse impacts of energy use are going to increase without appropriate and timely countermeasures. Restructuring towards more sustainable energyuse patterns would require large research and development (R\&D) efforts and determined policy measures. It is very capital intensive, requiring new forms of financing and many decades of capital turnover.

Protection of the atmosphere at the local, regional and global levels faces a number of competing social and economic policy concerns. Some of them have higher priorities such as the eradication of poverty, provision of adequate health care and employment opportunities and a number of other basic human needs. The challenge of protecting the atmosphere is further compounded by persistent scientific uncertainties concerning the exact nature of the interaction between human activities and the atmosphere and about the possible impacts of climate change, including the costs and benefits of adaptation and mitigation. 
The FCCC provides guidance for policies directed at protecting the atmosphere despite scientific uncertainties. This includes taking 'precautionary measures' especially where there are threats of 'serious irreversible damage'. The FCCC also states that the 'lack of scientific certainty should not be used as a reason for postponing such measures', that measures should be globally cost-effective, comprehensive and that they should take into account different socio-economic contexts [10].

\section{Energy for development}

Energy needs are driven by three principal factors: population growth, economic and industrial development and technological change. Energy can be seen as one of the fundamental requirements for economic growth and social improvements and not just a consequence of such growth. This section assesses the role of energy in economic development, energy-related environmental impacts as a function of the level of economic development and some salient preconditions for sustainable energy development.

\subsection{The role of energy in economic development}

Prior to the Industrial Revolution, the energy system relied on harnessing natural energy flows and animate and human power to provide the required energy services, in the form of heat, light and work. Power densities and availability were constrained by site-specific factors. Mechanical energy sources were limited to draught animals, water and windmills. Burning of fuel-wood and tallow candles were the only means of converting chemical energy to heat and light. Energy consumption typically did not exceed 0.5 toe (tons of oil equivalent) per capita per year [11].

Today, some two billion people still rely on similar traditional energy end-use patterns. They use traditional energy forms and technologies and have no or inadequate access to modern energy services. This severely constrains the satisfaction of basic needs: it precludes the modernization of economic structures and hinders human development.

Figures 2.1 shows the 1990 per capita energy consumption in a number of world regions by source and contrasts this with their respective populations. The height of the bars in Figure 2.1 is proportional to current capita energy use, the width of the bars is proportional to population size. Hence, the area of each bar is proportional to total energy use. The differences in the per capita primary energy consumption in the world are indeed very large. Less than a third of the world's population consume more than twothirds of global energy. Cumulative historical consumption is even more unevenly distributed: about $85 \%$ of all energy used to date has been consumed by less than $20 \%$ of all the people who have lived since 1850 . 
Figure 2.1 Primary energy use in 1990 (in toe ) by source, compared to population (in millions), for different world regions

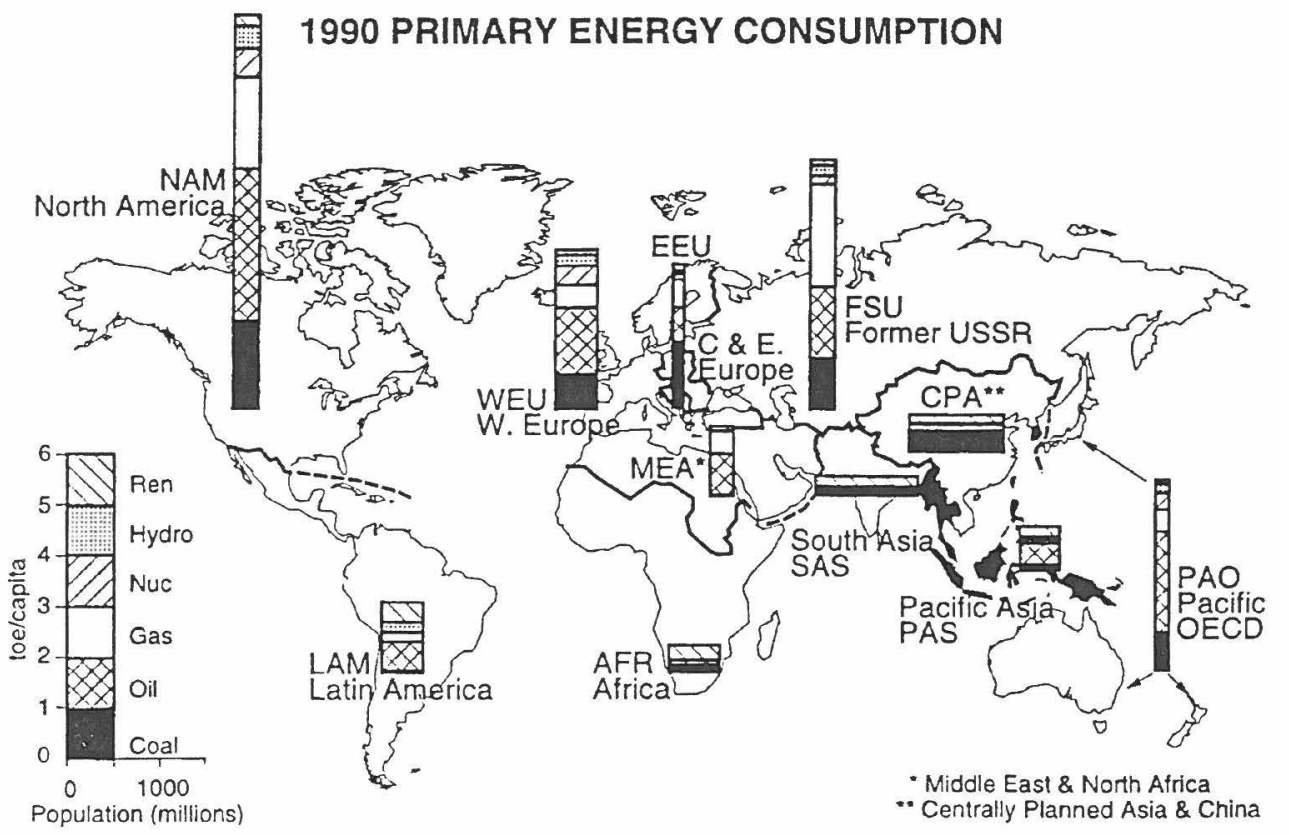

Source: [12]

Current per capita commercial energy consumption varies by a factor of more than 20 between North America and South Asia. For example, total primary energy use is about 0.4 toe per capita in Bangladesh. This is ten times lower than per capita use in Western Europe and the Pacific OECD and about 20 times lower than in North America. These disparities are even higher in the use of modern, commercial energy forms, i.e., excluding the consumption of traditional, non-commercial energy such as biomass. For example, commercial energy use is only 0.1 toe per capita in Bangladesh. This is nearly 100 times smaller than Canada with 9.4 toe per capita. Commercial energy use per capita can differ by as much as 500 between individual countries in the most extreme cases.

Western Europe and Japan have much lower per capita energy consumption when compared to North America with about the same levels of affluence. This indicates a substantial degree of diversity in energy consumption patterns even among industrialized countries. Disparities are also large among developing countries and they are even larger across different social and economic groups everywhere.

Another important difference is in the structure of energy supply. Developing countries rely primarily on coal and other solid fuels such as traditional and noncommercial biomass [13]. Most of the industrialized countries draw on large shares of crude oil and natural gas in their primary energy consumption; some regions have substantial contributions of nuclear energy and modern renewable sources.

There is a visible and statistically significant relationship between per capita energy consumption and per capita economic output across individual countries and regions and over time, despite the large differences in current and historical patterns of energy use. This relationship is shown in Figure 2.2. Economic output is measured in terms of Gross 
Domestic Product (GDP) both at prevailing market exchange rates (mer) and at purchasing power parities (ppp). The relationship holds for both measures. The main difference is that the purchasing power of consumers in developing regions and in economies in transition is higher than if measured in terms of international market exchange rates.

Figure 2.2 Primary energy (toe) per capita versus GDP per capita (US(1990)\$ at market exchange rates, $\mathrm{GDP}_{\mathrm{mer}}$, and purchasing power parities, $\mathrm{GDP}_{\mathrm{ppp}}$ ) for selected world regions and two historical trajectories for the USA (1800-1990) and Japan (1900-1990).

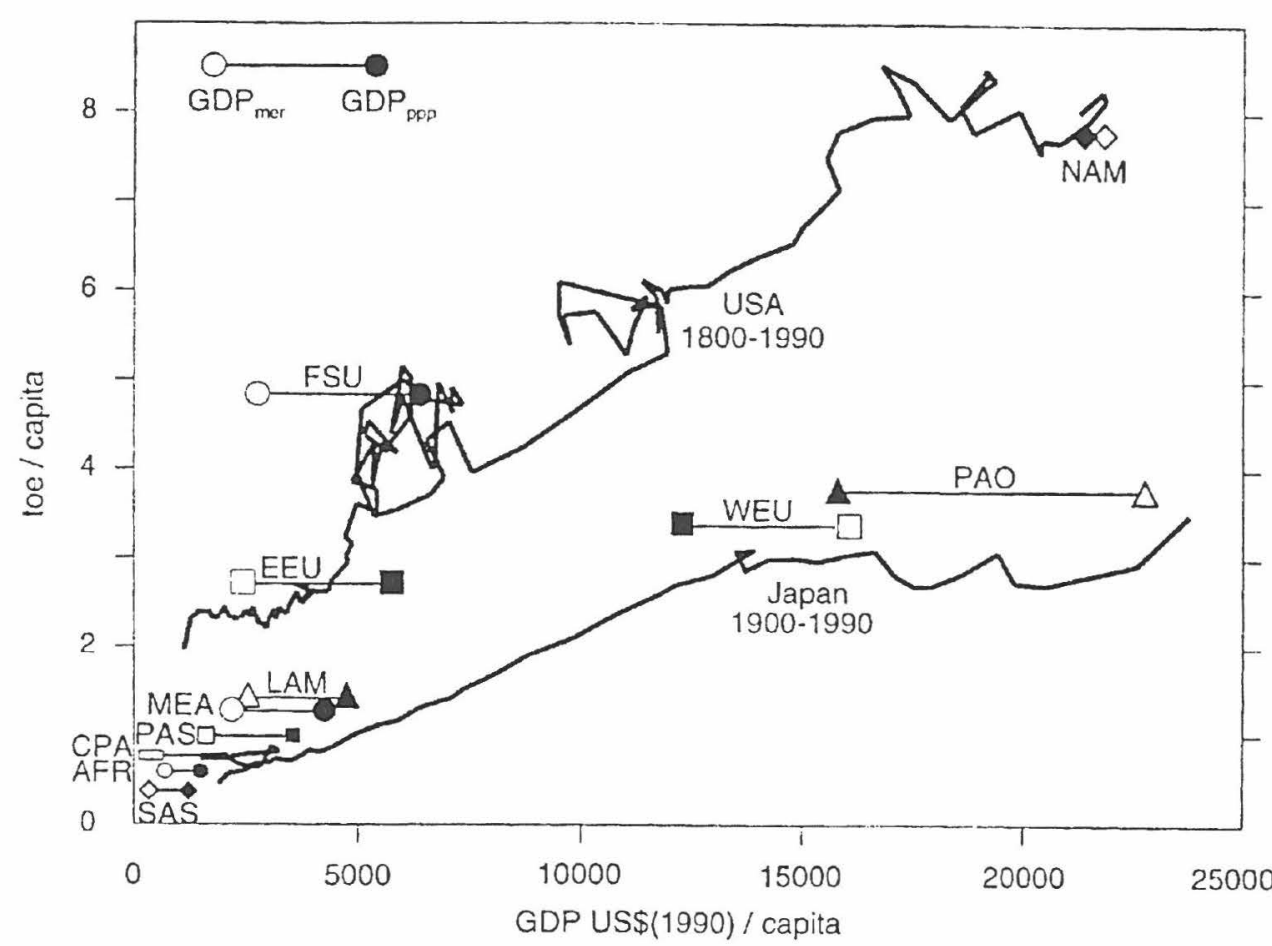

Source: Based on IEA, [14] and World Bank, [15] statistics. Historical data are based on Nakicenovic, [16] and Maddison, [17]. For explanation of regional abbreviations see Figure 2.1.

At one extreme are the countries with lowest income and also lowest per capita energy use. They include Subsaharan Africa (AFR) and South Asia (SAS). As incomes rise so does energy use. At intermediate levels of per capita economic output and energy use are the economies of North Africa and the Middle East (MEA), Pacific Asia (PAS) and Latin America (LAM). Current per capita primary energy use in some of the higher income economies of Asia already exceeds that of some OECD economies. For example, Hong Kong, South Korea and Taiwan consume more energy per person than Turkey, Spain, Portugal or Greece. Per capita energy use in Singapore is about the same as in the United Kingdom [18].

Although this pattern of growing energy use with economic development is pervasive, there is no unique and universal 'law' that specifies an exact relationship between economic growth and energy use. This depends on many specific and individual 
factors prevailing in a given country or region. It depends on historical development paths, natural resource endowments, settlement patterns, transport requirements, policy and tax structures and on many other geographic, climatic, economic, social and institutional factors. This also explains the persistent differences in energy-use patterns between countries and regions even at comparable levels of income. Different development pathways span all the extremes from 'high energy intensity' to 'high energy efficiency'. This is illustrated in Figure 2.2 with the development paths of the USA and Japan; they show no apparent signs of convergence. Per capita energy consumption is lower in Japan than in the USA; this was the case throughout the whole period of industrialization and at all levels of income.

\subsection{Environmental impacts of energy}

The type and extent of the environmental impacts of energy production and use are closely related to the degree of economic development and industrialization. This is illustrated in Figure 2.3. Three different classes of environmental problems are distinguished in the figure following a World Bank [19] classification. They include environmental problems of poverty, industrialization and affluence. Different phases of economic development place different burdens on the environment but economic development also enables societies to resolve environmental challenges. Different types of environmental problems call for different policy approaches and solutions.

Figure 2.3 A typology of environmental problems and strategies as they evolve with economic development

ENVIRONMENTAL PROBLEMS OF

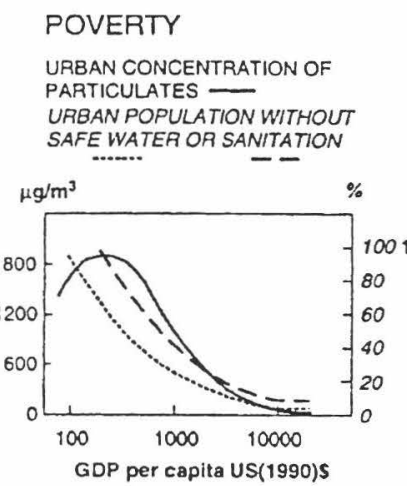

INDUSTRALIZATION

AVERAGE DEFORESTATION URBAN CONCENTRATIONS OF SULFUR DIOXIDE - -

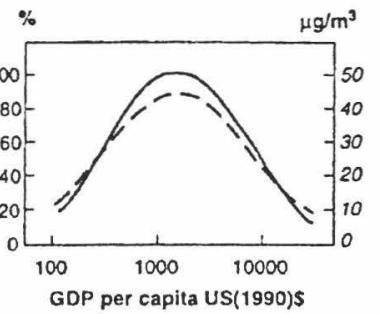

Impact on human health

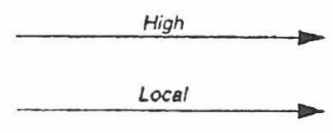

Hours, days

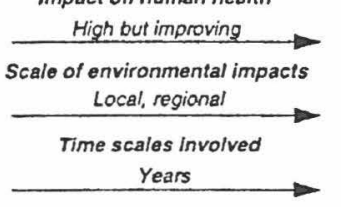

AFFLUENCE

CARBON EMISSIONS FROM ENERGY END USE PER CAPITA -

MUNICIPAL WASTE PER CAPITA - -
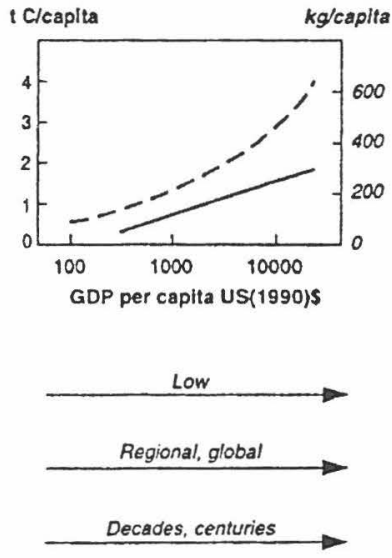

ENERGY - ENVIRONMENT STRATEGIES
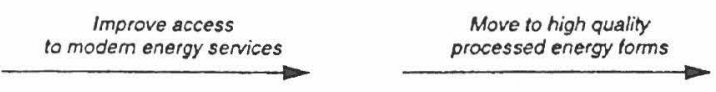

Eficiency improvements Decarbonization

Source: Adapted from World Bank, [19] 
Examples of environmental problems that result from poverty include inadequate sanitation, lack of clean drinking water, high levels of indoor and outdoor particulate matter air pollution. Indoor air pollution is largely due to (inefficient) burning of fuelwood in traditional open fireplaces. High outdoor particulate air concentrations are largely due to biomass and coal combustion and, to a lesser degree, to motorized traffic. Impacts are usually limited to those areas close to the source of pollution. Adverse impacts often include poor human health, sometimes also resulting in high mortality especially when it occurs in combination with poverty. The main and most effective policy response to these types of environmental problems is economic development itself. The eradication of poverty and increasing incomes improve accessibility to modern energy services that decrease indoor and particulate pollution. Human health generally improves with economic development.

The second category of environmental problems related to the process of industrialization includes high ambient concentrations of sulphur dioxide and high levels of hazardous industrial wastes. Problems emerge primarily in urban and industrial areas, but with increasing levels of industrialization they also spread to larger regions and start affecting many ecosystems in addition to impacting on human health. These environmental impacts can range in duration from days, such as urban smog, to much longer time spans in cases of regional-scale pollution like acid rain, toxification of river basins, or deforestation of whole regions.

The environmental problems associated with industrialization tend first to intensify and increase in magnitude and extent, they then reach a peak and thereafter decline. The increase during the initial phase of industrialization is due to the expansion of production and urbanization. The reasons for the decline are also related to economic development. Once basic economic needs are satisfied and income levels have increased, the amenities of a clean local environment become important social and economic objectives. Economic growth also provides the resources required to tackle environmental problems successfully. The policy measures required to resolve the environmental problems of industrialization need to combine incentives for a cleaner environment with regulatory mechanisms. Incentives need to further structural change toward more efficient use of energy and other resources including better energy end-use devices, cleaner fuels and improved public infrastructures, among others. Regulatory mechanisms inter alia include environmental standards, financial and tax incentives, control of large emissions point sources, and regular equipment maintenance and replacement.

The last category of environmental problems associated with economic development according to the above classification is related to affluence. Typical examples include ever-increasing volumes of municipal wastes and energy-related emissions of greenhouse gases, most notably carbon dioxide $\left(\mathrm{CO}_{2}\right)$. The direct impacts on human health (toxicity) are generally low. Environmental impacts are mostly of an indirect long-term nature, extending over decades to centuries. Their extent and exact nature are often uncertain; sometimes it is not clear whether environmental impacts are even occurring or will ever occur. Examples include climate change and loss of biodiversity. Spatial scales extend from the regional to the global level. In contrast to the first two categories, the environmental problems of affluence tend to become exacerbated with rising levels of income and consumption, and evidence is still outstanding as to whether municipal waste or carbon dioxide emissions might saturate with rising affluence. Hence, policy strategies need to be comprehensive and cover numerous economic activities; they need to promote 
long-term structural changes for production and consumption alike. There are generally no easy, quick 'technological fixes'.

Two important generic strategies to address environmental issues at high levels of income and consumption include improved energy efficiency and 'decarbonization' of energy, that is, changes towards cleaner fuel supply and end-use structures. Improved efficiency generally reduces resource use and environmental impacts across all pollutants and across all spatial and temporal scales. 'Decarbonization' also entails elements of multipurpose strategies as it can simultaneously reduce global, regional and local energyrelated pollution. In addition to efficiency improvements and cleaner energy, so-called 'end-of-the-pipe' pollution abatement systems have been successfully applied to large point sources and more recently to some mobile sources. These include sulphur and nitrogen scrubbers for power plants and catalytic converters for motor vehicles. These systems have the advantage that they can be effected relatively quickly. However, they have a more limited effect in reducing emissions than other more generic options, such as structural change. They tend to reduce one pollutant in one particular location, rather than have the broader impact of a switch to cleaner fuels or to inherently emission-free energy systems.

\subsection{Energy and sustainable development}

The notion of sustainable development concerns both current and future generations. For current generations, the first and foremost precondition for sustainable development is the eradication of poverty and satisfaction of basic human needs. Once these needs are satisfied, the next objective of sustainable development is to provide the basis for human choices. These involve many dimensions including cultural, social and economic. As such they cannot be resolved by scientific methods but are, of course, a question of values, preferences and policies. The same applies for future generations, albeit the uncertainties are larger because the social, cultural and economic contexts for future generations is unknown.

The necessary preconditions for sustainable development are:

1 avoidance of catastrophic events threatening the life support functions of the earth, including irreversible changes, and

2 provision of the means and capabilities for present and future generations to satisfy their basic needs and giving them the possibility of making choices about their lives beyond basic needs, including the capacity to adapt to changing social, economic and environmental conditions.

This means the transference of increased knowledge and know-how, technology and capital from the present to future generations. These transfers are compensation for the use of resources by current and past generations.

For sustainable energy development this implies making sufficient energy services available to every citizen of the planet now and in the future so that basic human needs can be satisfied. However, because the current energy system predominantly relies on fossil fuel use, this involves consuming resources. In order to compensate future generations for the consumption of depletable energy resources (coal, oil and gas) energy systems need to become more efficient, have a larger portfolio of technologies and 
options to choose from and have drastically lower environmental impacts at all levels from local to global.

Another prime energy objective in the context of sustainable development is to avoid irreversible changes while fulfilling the above goals. For example, things that must be avoided include: greenhouse gas emissions at levels that would provoke major disruptive changes in the climate system; sulphur emissions and deposition that surpass the critical loads at which food production can be sustained; and total consumption of all easily accessible fossil fuel resources, particularly higher grades of oil and gas. One way of interpreting the above conditions for sustainable energy development is to use fossil fuels as an endowment for preparing the necessary long-term transition towards a non-fossil, sustainable energy system.

Figure 3.1 Global primary energy use 1850 to present (Gtoe), by source and total (stacked totals)

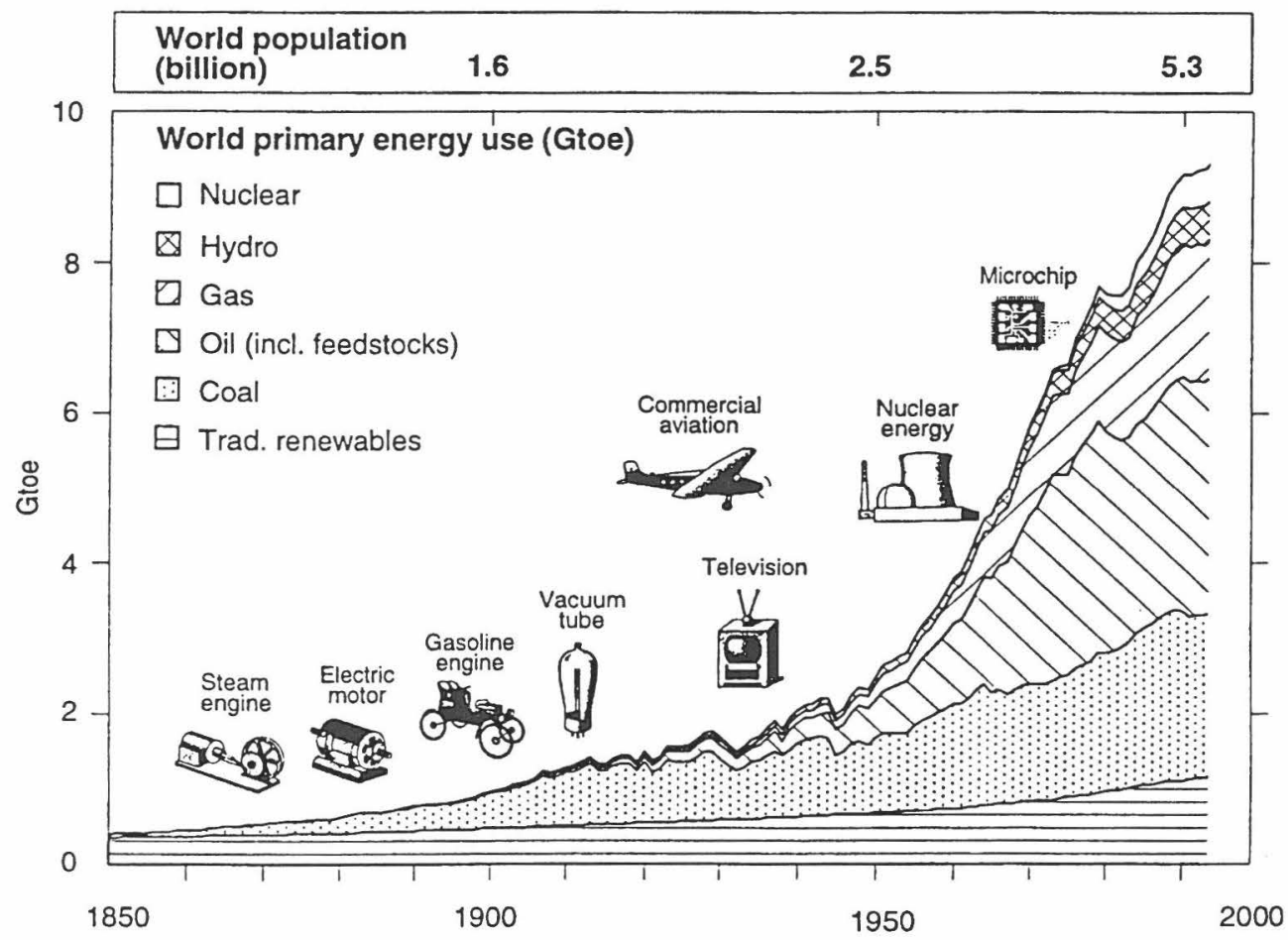

Source: Adapted from Davis, [20] and IIASA-WEC, [12]. For a discussion of data sources see Grübler [52].

\section{Trends in energy use}

Global primary energy use has increased by a factor of 20 since the middle of the nineteenth century; an average annual growth rate of $2.2 \%$ per year (Figure 3.1). Global primary energy use, including traditional fuels, around 1860 amounted to less than 0.5 Gtoe (gigatons \{billion tons \} oil equivalent). It took about 40 years to double this consumption: by the turn of the century global primary energy use surpassed one Gtoe and by the 1940s, 2 Gtoe. The next two doublings took only about 20 years each: by the 
early 1960s global energy use surpassed 4 Gtoe and exceeded 8 Gtoe at the beginning of the 1980s. In 1994 global primary energy use amounted to 9.1 Gtoe $[21,12]$.

There is a considerable variation in energy consumption growth rates over time and between different world regions. For example, global fossil energy consumption grew at 5\% per year between 1950 and 1970, at 2.3\% per year between 1970 and 1990, and at only $0.3 \%$ per year between 1990 and 1994 . At the same time, the mix of primary energy sources has changed dramatically.

The legacy of the tremendous expansion in the use of predominantly fossil fuels has, however, also become apparent. Since the onset of the Industrial Revolution the atmospheric concentration of carbon dioxide increased from $280 \mathrm{ppmv}$ (parts per million by volume) to 358 ppmv in 1994 (see Figure 1.1 above).

\subsection{The role of technological change}

The history of economic growth and development is mirrored by corresponding increases in energy use. In turn, the increased availability of energy has enabled economic and human development. The enormous growth in economic output and energy use was both driven and enabled by continuous structural and technological changes.

Since the onset of the Industrial Revolution, two 'grand transitions' have shaped structural changes in energy systems at all levels. The first was initiated with a radical technological end-use innovation: the steam engine powered by coal. The steam cycle represented the first conversion of fossil energy sources into work; it allowed energy services to be site independent since coal could be transported and stored as needed, and it permitted power densities that were previously only possible in exceptional locations of abundant hydropower. Stationary steam engines were first introduced for lifting water from coal mines, thereby facilitating increased coal production. Later, they provided stationary power for what was to become an entirely new form of organizing production: the factory system. Mobile steam engines, on locomotives and steam ships, enabled the first transport revolution as railway networks were extended to even the most remote locations and ships converted from sail to steam. Characteristic energy consumption levels during the 'steam age', approximately the mid-nineteenth century in the UK, were about 2 toe per capita per year. By the turn of the twentieth century, coal had replaced traditional non-fossil energy sources and supplied virtually all the primary energy needs of industrialized countries.

The second grand transition was the increased diversification of both energy end-use technologies and energy supply sources. Perhaps the most important single innovation was the introduction of electricity as the first energy carrier to be easily converted to light, heat or work at the point of end use. A second key innovation was the internal combustion engine that revolutionized individual and public transport through the use of cars, buses and aircraft. Like the transition triggered by the steam engine, this 'diversification transition' was led by technological innovations in energy end use, such as the electric light bulb, the electric motor, the microchip and the computer, the internal combustion engine and aircraft. However, changes in energy supply have been equally far-reaching. In particular, oil emerged from being an expensive curiosity at the end of the nineteenth century to reaching the dominant global position it has occupied for the last 30 years. 


\subsection{Historical trends by energy source}

The dynamics of structural changes in the global energy system are illustrated in Figure 3.2 , showing the relative shares of different primary energy sources in the global primary energy supply. Structural changes of the global energy system can be characterized by relatively slow rates of change, which are typical for infrastructures. It took about half a century before coal was replaced by crude oil as the dominant global energy source. At the global level, the 'time constant' for fundamental energy transitions has been in the order of 50 years. At a regional level and for individual energy technologies and devices, the characteristic time constants are usually shorter as a result of faster capital turnover, among other factors [22].

Figure 3.2 Shares of different primary energy sources in global energy supply: 1850 to present, in percent. The data on traditional renewables are uncertain

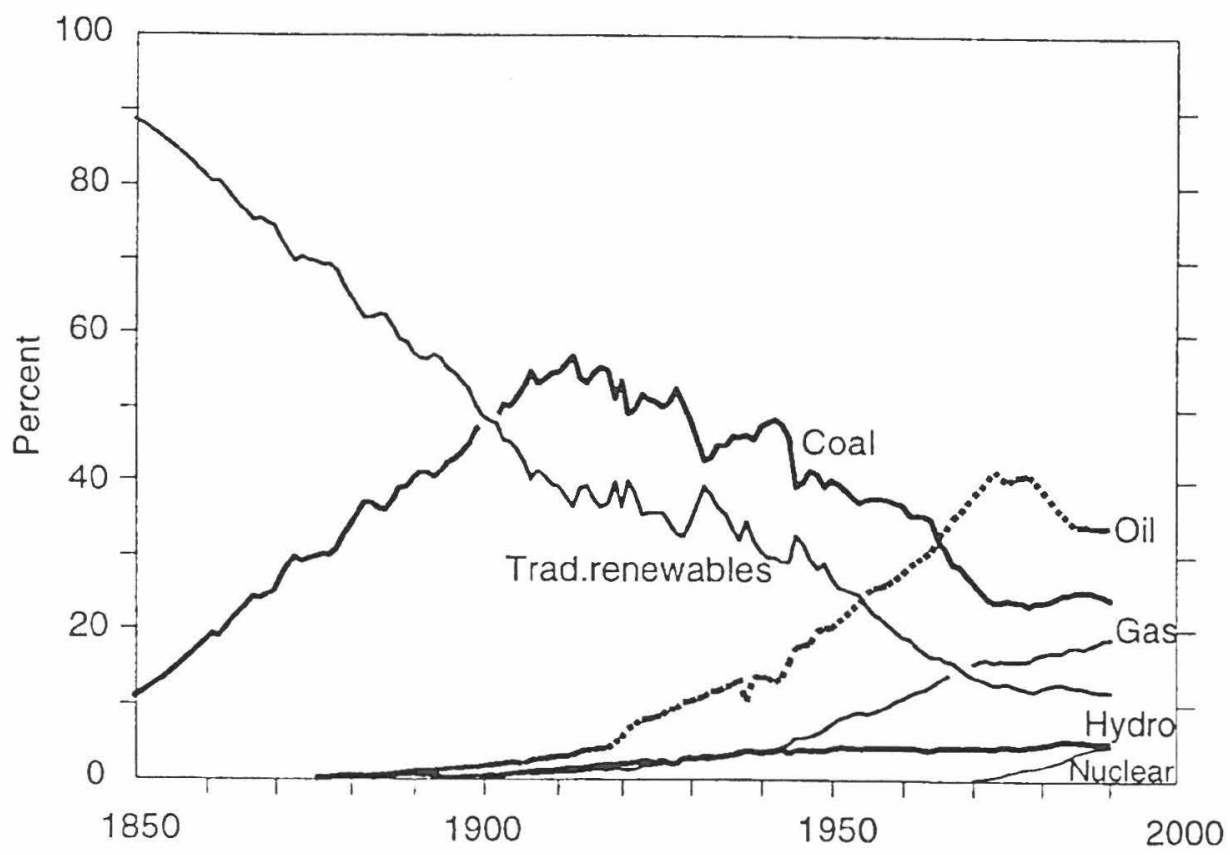

Source: IIASA-WEC, [12] and BP, [21]

The lifetime of energy equipment, and hence the turnover and capital stock replacement rate, is generally shorter the closer the equipment is to the end-user. Typical end-use devices such as light bulbs are usually replaced within one year. Household devices, e.g., stereo equipment, within ten years and residential capital equipment, e.g., boiler for a heating system, within 20 years. Conversely, the lifetimes of energy facilities are much longer: fossil power plants and renewable energy projects in the range of 30 years. Yet longer useful lives are observed for large hydro-schemes (dams) and for infrastructures (railway lines, roads, underground cables). The representative lifetime of energy facilities of 30 to 50 years implies that the totality of the energy sector capital stock will be replaced at least twice before the end of the twenty-first century offering numerous 
opportunities for efficiency improvements and for restructuring the energy system away from fossil fuels.

\subsection{Trends in energy use by sector}

Sectoral energy use patterns vary considerably across different world regions and countries. From 9 Gtoe primary energy consumed worldwide in 1990, about 6.5 Gtoe were delivered to final use, implying an overall primary to final energy conversion efficiency of about $72 \%$. The 6.5 Gtoe final energy is divided unequally among sectors. The largest share of about $40 \%$ is due to combined energy use in agriculture, households and commercial sectors, including the direct use of traditional, non-commercial fuels collected and consumed locally. The next largest share of about $31 \%$ is accounted for by industrial energy uses and another $6 \%$ by industrial feedstock requirements (non-energy uses of fossil fuels). Globally, the transport sector has the lowest share of about $23 \%$ in all final energy use, but the highest growth rate of all sectoral energy uses [23]. Table 3.1 disaggregates this global situation in 1990 by major developing world regions and by three global 'macro-regions' as defined by the Climate Convention: the OECD, the reforming (transition) economies (REFs) and the developing countries (DCs). Table 3.2 gives the corresponding average annual growth rates between 1970 and 1990.

In the OECD countries, final energy consumption is almost equally distributed among the three sectoral uses given in Table 3.1. In the reforming economies, industrial uses account for by far the largest share and in developing countries, agricultural, household and commercial activities. In both the OECD and developing countries, the highest rates of growth are transportation energy requirements. Industrial energy use has actually decreased in the OECD countries. In contrast, industrial energy use is growing rapidly in developing countries due to economic development and industrialization.

Table 3.11990 primary and final energy use by sector, for three world macro-regions and for six developing regions, in Mtoe

\begin{tabular}{lrrr|rrrrrr|r}
\hline & OECD $^{a}$ & REFs $^{b}$ & \multicolumn{1}{c}{ DCs } & \multicolumn{1}{c}{ AFR } & MEA & \multicolumn{1}{c}{ CPA } & SAS & PAS & \multicolumn{1}{c}{ LAM } & WORLD \\
Primary & 4181.0 & 1738.8 & 3056.2 & 287.5 & 348.5 & 944.8 & 443.7 & 424.0 & 607.8 & 8976.0 \\
\hline Final incl. & 2881.2 & 1200.0 & 2368.7 & 221.8 & 237.8 & 751.0 & 356.4 & 343.4 & 458.3 & 6449.9 \\
Industry & 799.6 & 551.7 & 676.3 & 33.3 & 71.4 & 338.9 & 74.6 & 67.3 & 90.9 & 2027.6 \\
Transport & 907.8 & 167.0 & 380.1 & 24.9 & 106.8 & 49.1 & 35.6 & 56.3 & 107.5 & 1454.8 \\
Others $^{d}$ & 918.1 & 433.0 & 1249.6 & 160.7 & 50.3 & 355.9 & 241.4 & 205.2 & 236.1 & 2600.7 \\
Feedstocks $^{\mathrm{c}}$ & 255.7 & 48.3 & 62.7 & 2.9 & 9.3 & 7.2 & 4.9 & 14.6 & 23.8 & 366.7 \\
\hline
\end{tabular}

Source: Based on IEA, [14] statistics and WEC, [24]

For definitions of regional abbreviations see Figure 2.1

${ }^{a}$ FCCC Annex II countries.

${ }^{b}$ FCCC Annex I countries undergoing the process of transition to a market economy.

'Developing countries

${ }^{\mathrm{d} I n c l u d e s}$ non-commercial fuels.

'Non-energy uses. 
Table 3.2 Primary and final energy use by sector, for three world macro-regions and for six developing regions. Average annual growth rates 1970-1990

\begin{tabular}{lccc|cccccc|c}
\hline & OECD & REFS & DCS & AFR & MEA & CPA & SAS & PAS & LAM & WORLD \\
Primary & 1.3 & 2.6 & 4.5 & 3.5 & 7.7 & 4.7 & 4.2 & 4.1 & 3.8 & 2.5 \\
\hline Final incl. & 0.9 & 2.2 & 4.0 & 2.9 & 7.4 & 4.3 & 3.7 & 3.3 & 3.4 & 2.1 \\
Industry & -0.4 & 1.6 & 4.2 & 2.2 & 6.7 & 3.3 & 6.2 & 7.4 & 4.5 & 1.4 \\
Transport & 2.2 & 2.0 & 5.8 & 2.1 & 11.8 & 5.3 & 4.0 & 7.7 & 3.9 & 2.9 \\
Others & 0.7 & 3.2 & 3.3 & 3.2 & 3.6 & 5.2 & 3.1 & 2.3 & 2.6 & 2.2 \\
Feedstocks & 2.0 & 2.7 & 7.9 & 5.2 & 8.2 & 20.8 & 1.5 & 10.7 & 7.8 & 2.7 \\
\hline
\end{tabular}

Numbers in italics indicate growth rates above average

Date source: see Table 3.1

\subsection{Trends in energy patterns by region}

Much of the historical increase in global primary energy consumption has occurred in the more developed countries. While they still consume two thirds of all primary energy, their share is declining as the world develops. Energy consumption is growing rapidly, especially in the economies undergoing vigorous development in some regions of Asia and most of the increases in future energy consumption can be expected to occur in what are now developing countries.

Figure 3.3 Global fossil primary energy use since 1850, industrialized versus developing countries, in Gtoe.

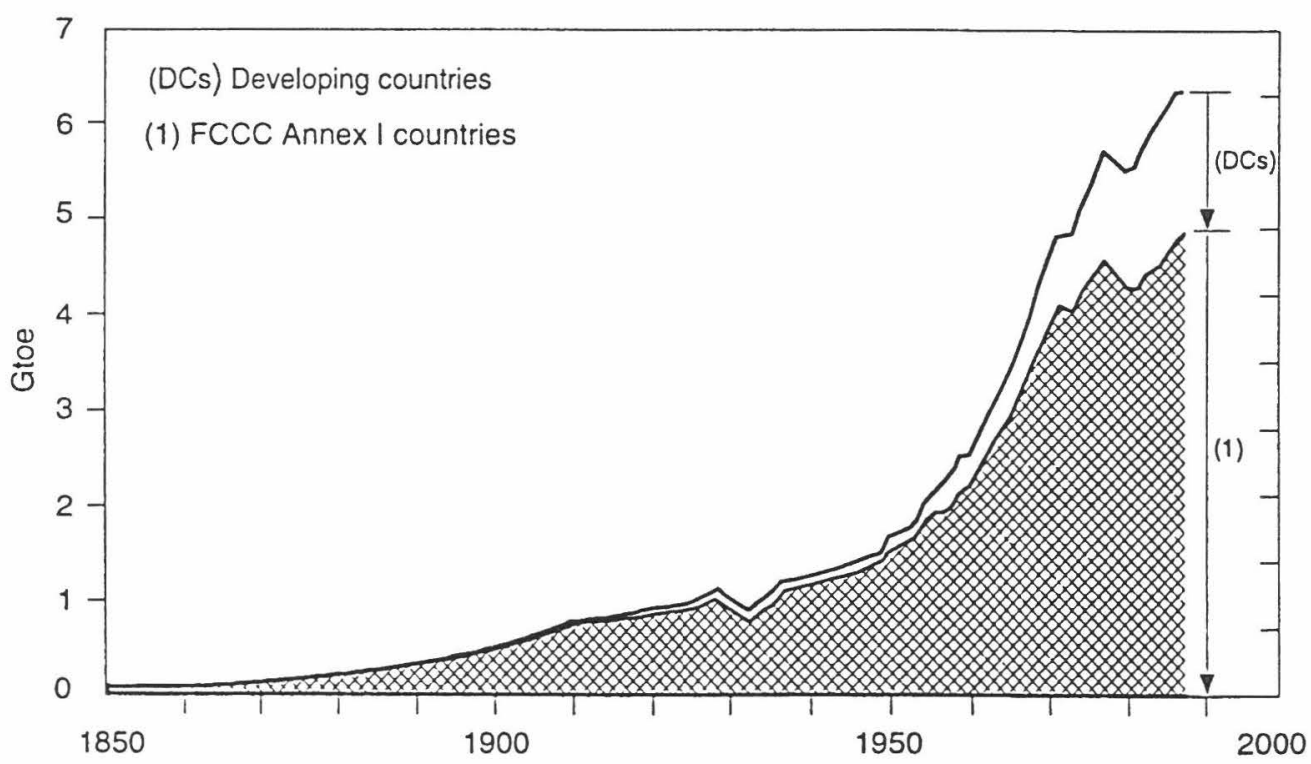

Source: Based on data in Grübler and Nakicenovic, [25] and Fujii, [26]. 
Figure 3.3 shows global primary energy consumption since 1850 disaggregated into industrialized and developing countries. It clearly illustrates that most of the historical and present energy consumption is indeed accounted for by the now industrialized regions of the world. It also shows that during most of the present century, growth rates of energy consumption in the developing economies exceeded those of the industrialized countries by a wide margin, albeit at substantially lower absolute consumption levels.

Table 3.3 documents some of these differences in the levels of primary energy use and the average annual growth rates between three 'macro-regions' of the world. Especially high are the growth rates of fossil energy consumption in the developing countries, in particularly during the 1950 s and 1960 s, averaging almost $9 \%$ per year. This illustrates the rapid replacement of traditional by commercial (fossil) energy forms in addition to and beyond the increase in energy consumption along with economic development in these regions. Although the growth rates have slowed down over the last decade, this process still continues today.

Table 3.3 Levels of total primary energy use, total and fossil energy (in parentheses) in Gtoe (top part) and average annual growth rates for selected periods, in percent per year (bottom part) for three macro-regions of the world as defined by the Climate Convention.

\begin{tabular}{|c|c|c|c|c|c|c|}
\hline In Gtoe & 1850 & 1900 & 1950 & 1970 & 1990 & $1994^{b}$ \\
\hline $\mathrm{OECD}^{c}$ & $.4(<.1)$ & $.9(.5)$ & $1.4(1.2)$ & $3.1(2.8)$ & $4.2(3.4)$ & $4.4(3.7)$ \\
\hline $\mathrm{REFs}^{\mathrm{d}}$ & - & $-(<.1)$ & $.3(.3)$ & $1.0(1.0)$ & $1.7(1.6)$ & $1.4(1.2)$ \\
\hline $\mathrm{DCs}^{\mathrm{e}}$ & - & $-(<.1)$ & $.4(.1)$ & $1.1(.6)$ & $3.1(1.9)$ & $3.3(2.2)$ \\
\hline \multirow[t]{2}{*}{ World } & $>.4(<.1)$ & $>.9(>.5)$ & $2.1(1.6)$ & $5.2(4.4)$ & $9.0(6.9)$ & $9.1(7.0)$ \\
\hline & $1850-1900$ & $1900-1950$ & $1950-1970$ & $1970-1990$ & $1990-1994$ & $\begin{array}{c}\text { Total } \\
\text { period }^{f}\end{array}$ \\
\hline $\mathrm{OECD}^{\mathrm{c}}$ & $-(4.6)$ & $-(2.0)$ & $4.0(4.2)$ & $1.6(1.0)$ & $1.4(1.7)$ & $2.7(2.5)$ \\
\hline $\mathrm{REFs}^{\mathrm{d}}$ & - & $-(4.1)$ & $5.7(6.4)$ & $2.8(2.4)$ & $-6.4(-7.2)$ & $3.2(4.1)$ \\
\hline $\mathrm{DCs}^{\mathrm{c}}$ & - & $-(3.8)$ & $5.1(8.9)$ & $5.1(6.3)$ & $2.3(3.2)$ & $4.8(6.9)$ \\
\hline World & $1.7(4.9)$ & $1.7(2.3)$ & $4.5(5.0)$ & $2.8(2.3)$ & $0.4(0.3)$ & $2.2(3.5)$ \\
\hline
\end{tabular}

${ }^{\mathrm{a}}$ Include feedstock uses of energy, and non-commercial and renewable energy

'Preliminary data

${ }^{c}$ FCCC Annex II countries

${ }^{\mathrm{d}}$ FCCC Annex I countries undergoing the process of transition to a market economy

${ }^{e}$ Developing countries

'Period for which data are available

\subsection{Energy intensities of economic activities}

Another important effect of economic development and technological change is their impact on energy intensities. Energy intensities express the amount of energy required per unit of economic output, usually measured by GDP, either for the economy at large or for particular sectors/activities. The principal impact of technological change is that it stimulates efficiency improvements and structural changes in economic activities, thus generally lowering energy intensities. 
The causes of energy intensity decreases are many and complex. They include, first, technological improvements in individual energy end use and conversion components for example, a more efficient stove or a more efficient power plant; structural shifts in the energy system, such as moving from coal-fired electricity generation to a gas-fired combined cycle plant; and interfuel substitution at the level of energy end use, like the replacement of fuel-wood by Liquid Petroleum Gas (LPG). They include economic shifts from more to less energy-intensive activities, and changing patterns of energy end uses, and ultimately, changing lifestyles. Not every change in every one of these categories represents a decrease in energy intensity but taken together, the overall trends are persistent and pervasive.

Figure 3.4 illustrates the scale of energy intensity improvements since the onset of the Industrial Revolution for total and commercial primary energy, respectively. Energy intensities for developing and transitional economies are expressed per unit of GDP based on market exchange rates $\left(\mathrm{GDP}_{\text {mer }}\right)$ and based on purchasing power parities $\left(\mathrm{GDP}_{\mathrm{ppp}}\right)$.

Figure 3.4 Primary energy intensity for selected countries, total and commercial energy, in kgoe per US(1990)\$. Intensities are given both for $\mathrm{GDP}_{\text {mer }}$ and $\mathrm{GDP}_{\mathrm{ppp}}$. (For USA and Japan $\left.\mathrm{GDP}_{\mathrm{mer}} \approx \mathrm{GDP}_{\mathrm{ppp}}\right)$

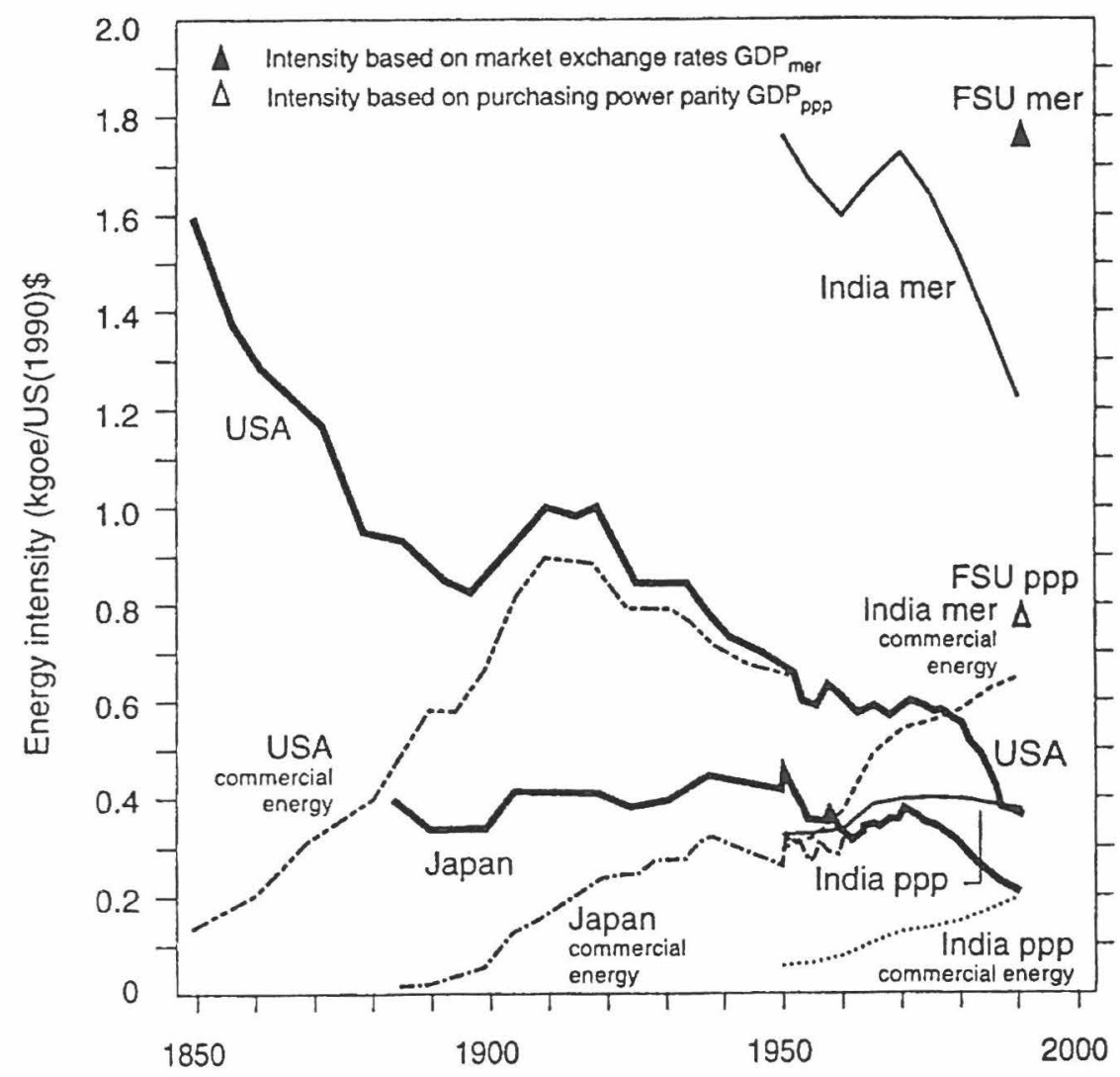

Data sources: Nakicenovic, [27]; Martin, [28] and TERI, [29] 
Aggregate energy intensities, including noncommercial energy, generally improve over time and this is true in all countries. A unit of GDP in the USA, for example, now requires less than one-fifth of the primary energy needed 200 years ago [27]. This corresponds to an average annual decrease in energy intensity of roughly one percent per year. The process is not always smooth, as data from other countries illustrate. Periods of rapid improvements are interlaced with periods of stagnation. Energy intensities may even rise in the early takeoff stages of industrialization, when an energy and materialsintensive industrial and infrastructure base needs to be developed.

While aggregate energy intensities generally improve over time, commercial energy intensities follow a different path. They first increase, reach a maximum and then decrease. The initial increase is due to commercial energy carriers substituting for traditional energy forms and technologies. Once that process is largely complete, commercial energy intensities decrease in line with the pattern found for aggregate energy intensities. Because most statistics document only modern, commercial energy use, this 'hill of energy intensity' has been discussed frequently in the literature (e.g. [30]). Its existence in the case of commercial energy intensities, however, does not diminish the power of the result for aggregate energy intensities - there is a decisive, consistent long-term trend toward improved energy intensity across a wide array of national experiences.

History matters. While the trend is one of conditional convergence across countries, the patterns of energy intensity improvements in different countries reflect their different situations and development histories. Economic development is a cumulative process, incorporating in different countries different consumption lifestyles, different settlement patterns and transport requirements, different industrial structures and different takeoff dates into industrialization. Thus the evolution of national energy intensities is path dependent. In Figure 3.4, for example, there is an evident distinction between the "high intensity' energy development trajectory of the USA and the 'high efficiency' trajectory of Japan.

\subsection{Carbon dioxide emissions and carbon intensities}

Energy extraction, conversion and end use impact on the environment at all levels: local, regional and global. At the global level, the emissions of so-called greenhouse gases could possibly lead to irreversible global climate change. Energy is the most important single source of greenhouse gases. It contributes about two thirds of all anthropogenic sources of carbon dioxide emissions, the most important of all greenhouse gases and is also a major source of methane, the second most important greenhouse gas.

Figure 3.5 shows 1990 per capita, energy-related and non-energy (e.g., deforestation) carbon dioxide emissions in a number of world regions by source and relates these to the respective population size. The area of each bar is proportional to total carbon dioxide emissions in the particular region. The current levels of per capita, fossil-fuel carbon emissions across the world regions differ by a factor of 30 . A persistent per capita emission gap remains even after including carbon emissions from land-use changes, currently concentrated in tropical latitudes. 
Figure 3.51990 per capita $\mathrm{CO}_{2}$ emissions (tons $\mathrm{C}$ per capita) per region and source, fossil fuels and range for biota sources compared to population (million)

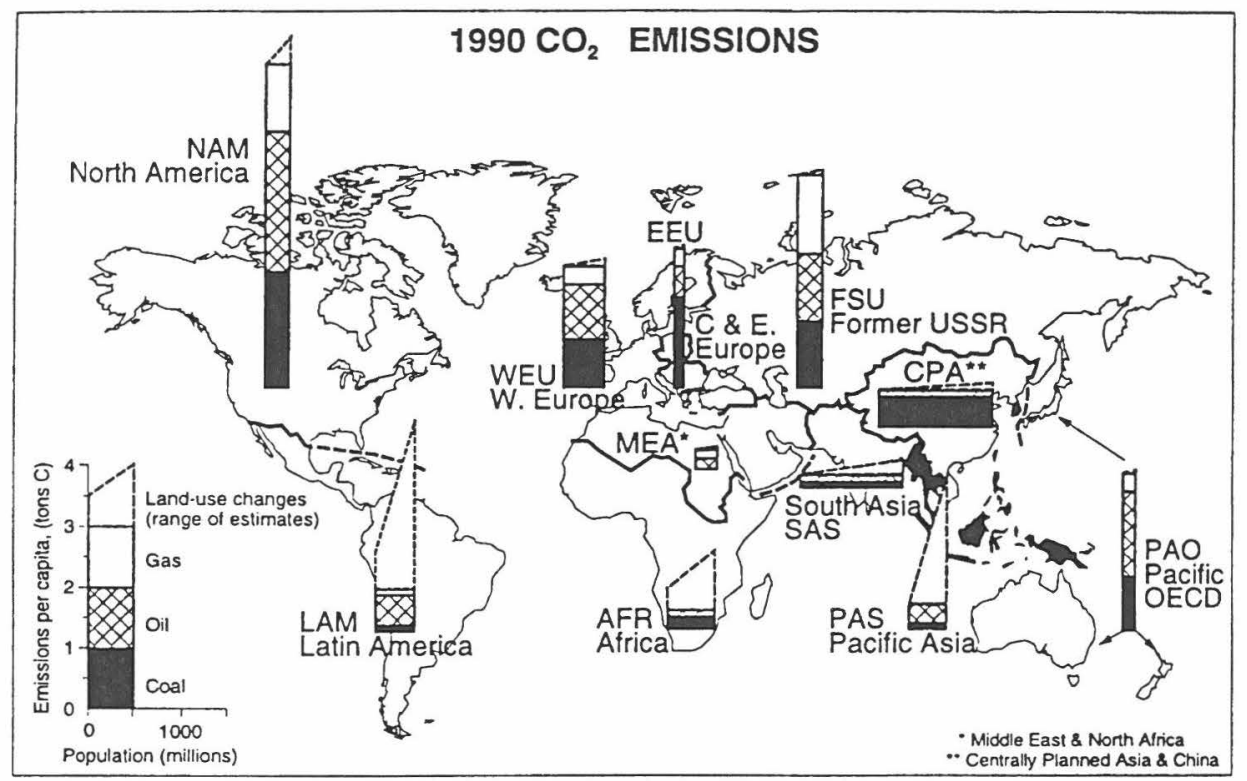

Source: IPCC SAR WG II, [22]

Figure 3.6 shows the history of global energy-related carbon dioxide emissions by major source of primary energy. The largest single source of fossil fuel carbon emissions is coal, with currently about a $43 \%$ share, followed by oil with about $39 \%$ and natural gas with $18 \%$. Adding non-energy uses of fossil fuels, such as industrial feedstocks, reverses the shares to $40 \%$ for coal and $42 \%$ for oil.

Figure 3.6 Global fossil energy emissions by source (stacked totals). Emissions also include fuelwood, that if used sustainably does not contribute to atmospheric concentration increase

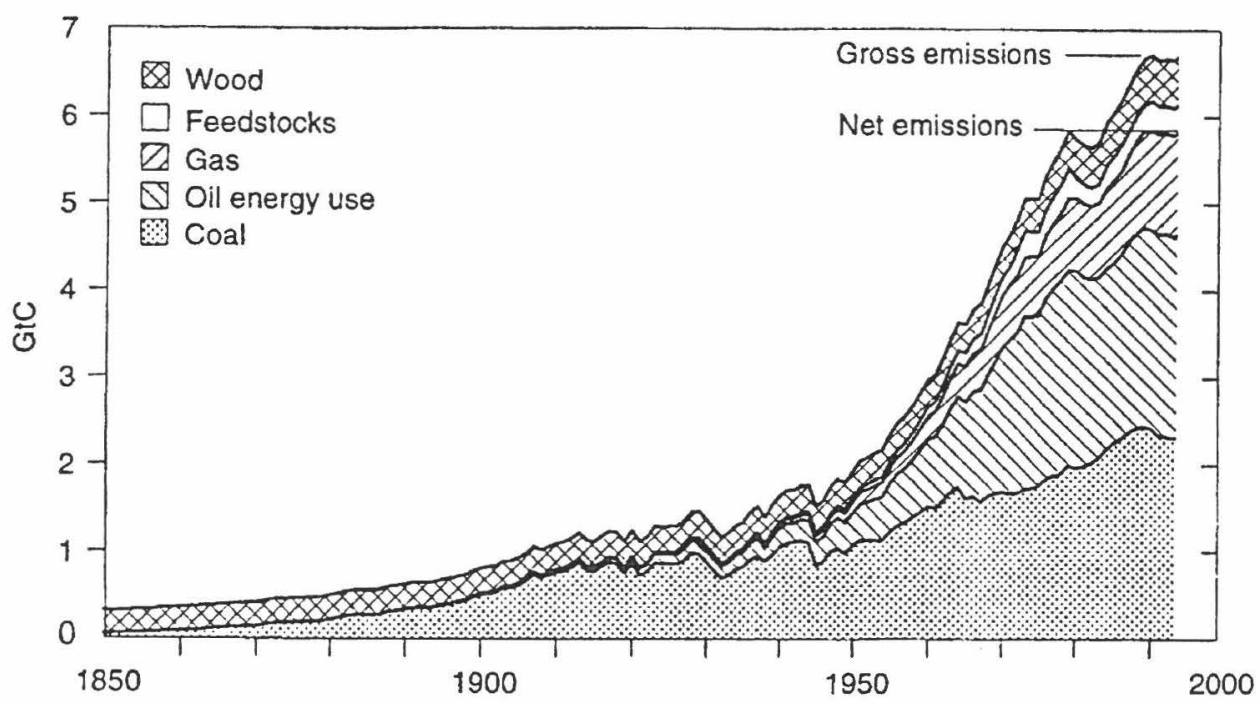

Source: Based on Figure 3.1 
Figure 3.7 shows the process of 'decarbonization' as the decreasing carbon intensity of primary energy, that is, the ratio of average carbon emissions per unit of primary energy. The ratio decreases due to the continuous replacement of fuels with high carbon contents, such as coal, by those with lower carbon content or carbon-free sources such as renewables and nuclear energy. At the global level, decarbonization of energy occurs at a slow rate of about $0.3 \%$ per year. This falls short by about $1.9 \%$ of what would be required to offset the effects of the long-term, global growth in primary energy consumption of about $2.2 \%$ per year. This means that global carbon dioxide emissions have been increasing at close to $2 \%$ per year, implying - in the absence of policy measures - a doubling before the 2020s. This is, in fact, quite close to the emission levels projected in many of the global 'business as usual' emissions scenarios [31]

Figure 3.7 Carbon intensity of global primary energy $1850-1990$ in tons $C$ per toe

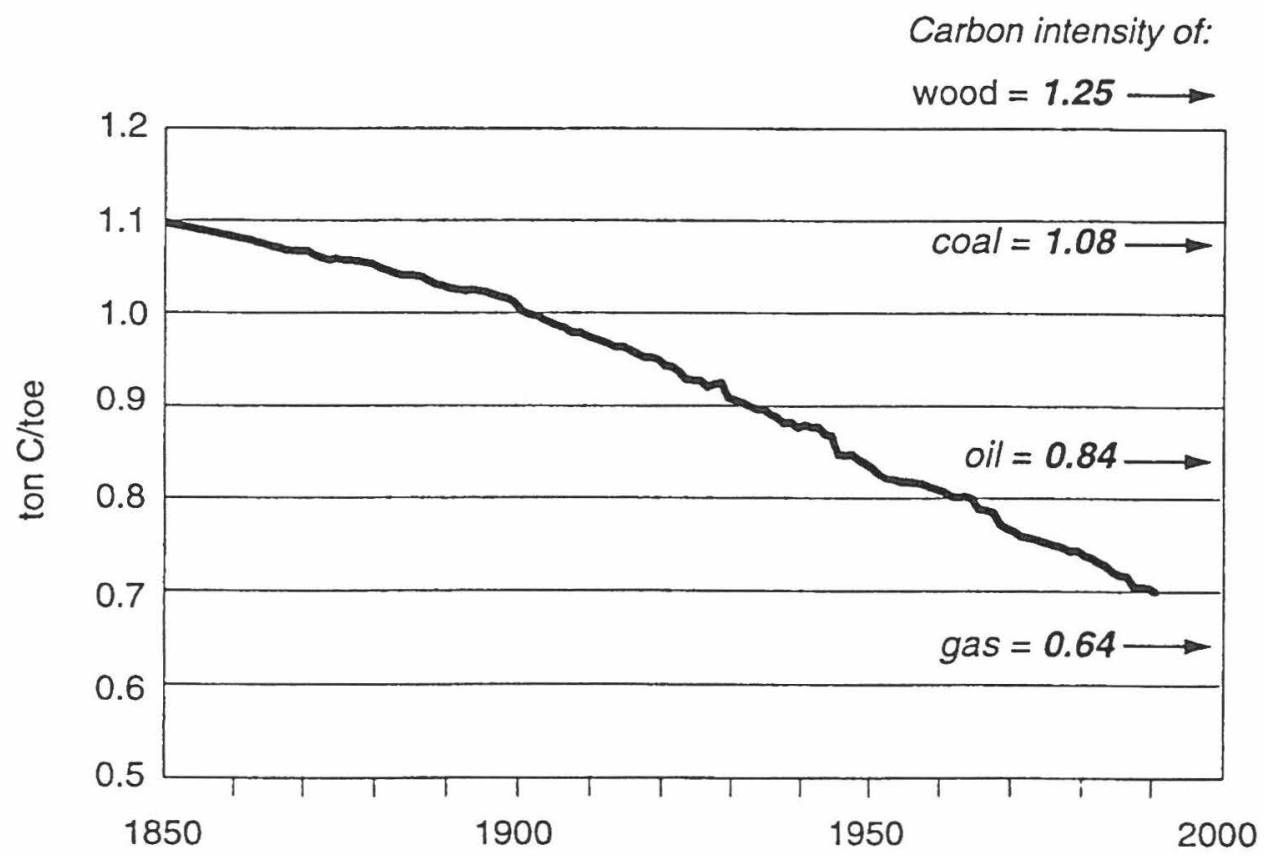

Source: Nakicenovic, [32]

Five representative countries have been selected here to demonstrate the different national experiences in carbon intensities. For example, the USA has one of the highest energy intensities of the industrialized countries and also one of the highest per capita carbon emissions in the world. France and Japan, on the other hand, have among the lowest carbon intensities but for different reasons: in Japan this has been achieved largely through structural changes in the energy system by substituting coal with oil and natural gas, and in France largely through the vigorous substitution of fossil fuels by nuclear energy. Finally, China and India represent two rapidly developing countries where the replacement of traditional by fossil energy is still incomplete, resulting in very high energy and carbon intensities. Together, these five countries account for almost half of the global energy consumption and energy-related carbon dioxide emissions. Figure 3.8 
shows the historical evolution of carbon intensity of energy for these five countries. It is noteworthy that decarbonization has occurred in all of these five countries despite their diversity. However, without continuing structural changes in the energy system towards less carbon intensive and carbon free sources of energy, trend reversals cannot be excluded in the future.

Figure 3.8 Carbon intensity of primary energy for selected countries, in tons $\mathrm{C}$ per toe

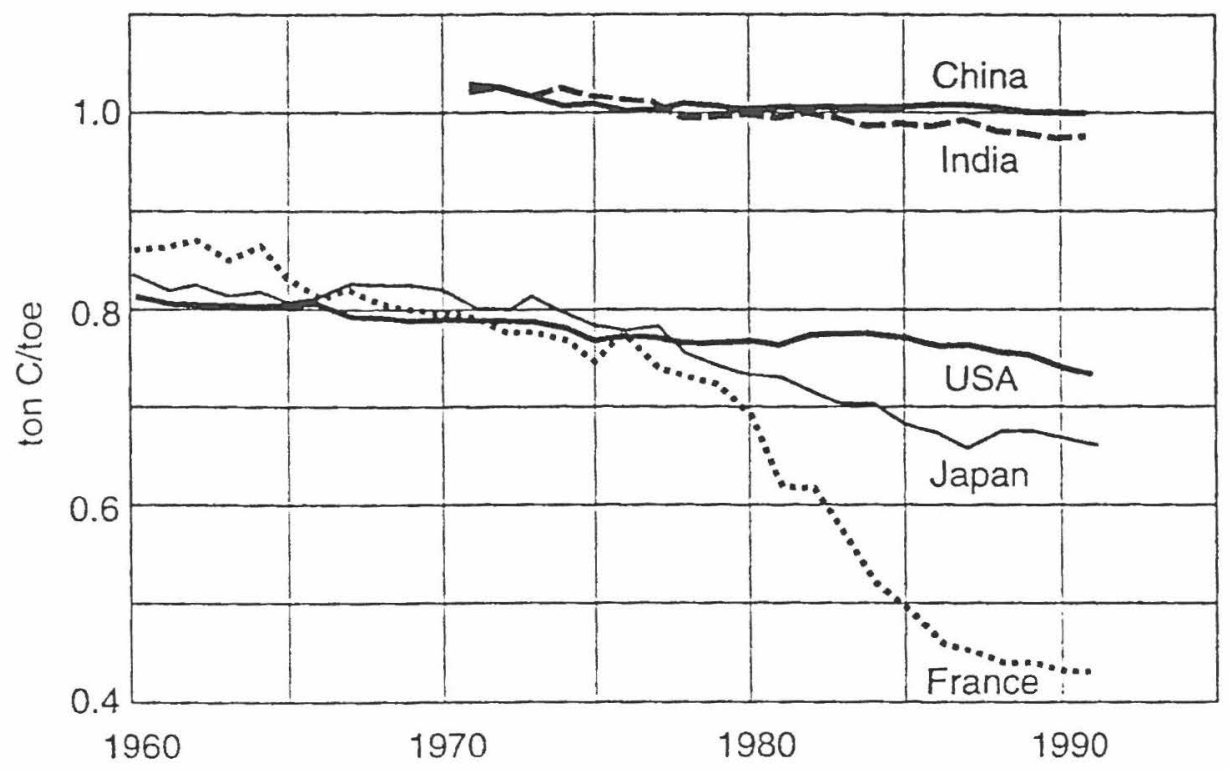

Source: Nakicenovic, [32]

\subsection{Contributions to atmospheric concentration increases}

The industrialized countries account for some $70 \%$ of the present carbon dioxide emissions. They are also responsible for most of the historical emissions. Although at much lower absolute levels, the emissions of developing countries are growing more rapidly than in the industrialized ones. Figure 3.9 shows the history of fossil energy carbon dioxide emissions by major world regions. Some $240 \mathrm{GtC}$ (Gigatons, or billion tons, of elemental carbon) have been released into the atmosphere by energy-related activities. This is much larger than the estimated carbon release from deforestation and land-use changes over the same period of some $120 \mathrm{GtC}$ [33]. 
Figure 3.9 Global energy-related carbon emissions by major world region (stacked totals), in GtC

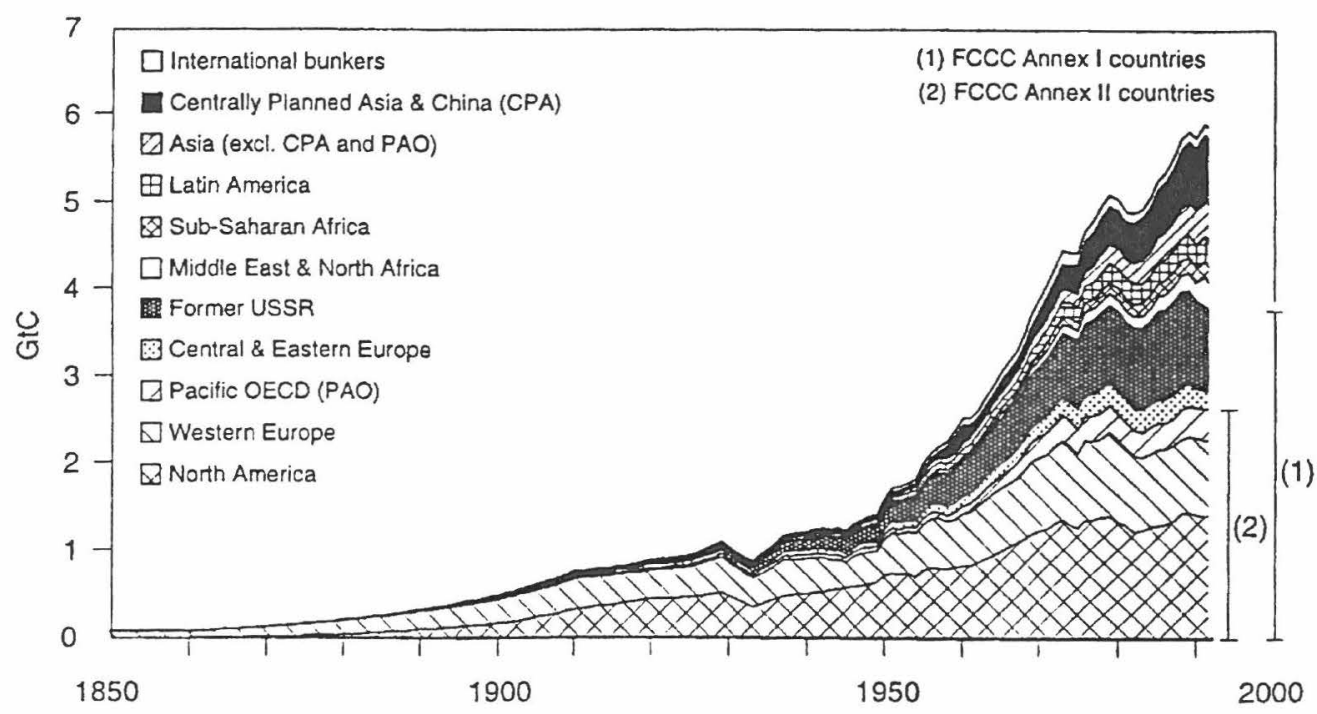

Source: SAR WG II, [22]

The significant divide between developed and developing countries in current fossil energy carbon emissions becomes even larger when considering their historical dimension: because of the long lifetime of atmospheric carbon, estimates indicate that about $84 \%$ of the fossil energy carbon dioxide emissions since 1800 still remaining in the atmosphere can be attributed to the past emissions of the now industrialized countries [25]. Some of the carbon dioxide emitted by James Watt's first steam engine is still airborne. At the other extreme, the share of developing countries in energy related atmospheric carbon dioxide buildup is, at $16 \%$, very low, especially in view of the fact that about $70 \%$ of the people that have lived on earth since 1800 reside(d) in these countries [25]. The upper part of Figure 3.10 summarizes the regional breakdown of energy-related carbon dioxide emissions at the end of the 1980s, and the lower part shows the contribution of each region to atmospheric concentration increases over the entire period since 1800 .

The significant differences in historical contributions to atmospheric concentration increases between industrialized and developing countries are somewhat reduced when the analysis is extended to all sources and species of greenhouse gases. Nevertheless, the preponderance of the industrialized countries persists [25]. The differences in recent and historical shares of the potential 'global warming pie' between regions illustrate the implications of considering the actions of past generations, in addition to the responsibilities to be assumed by present and future generations, in climate change mitigation and adaptation efforts (see [26]). This asymmetry is also reflected in the FCCC through the concept of 'common, but differentiated responsibilities' and the specific commitments contained in the Convention for industrialized countries [10], particularly those not undergoing a process of transition to a market economy (FCCC Annex II countries, corresponding to the OECD members with the exception of Mexico). 
Figure 3.10 Shares (in percent) of different world regions in current (top) and their contribution to historical (Since 1800) concentration increases of energy-related carbon emissions

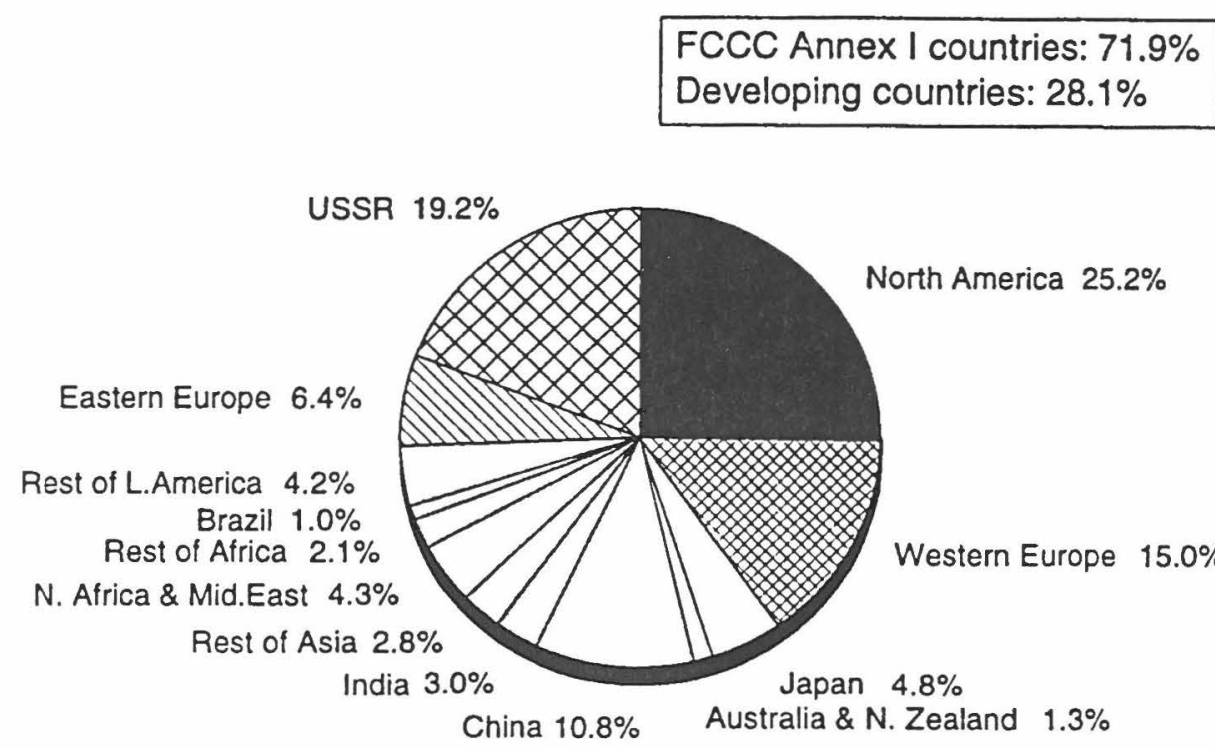

FCCC Annex I countries: $83.7 \%$

Developing countries: $16.3 \%$

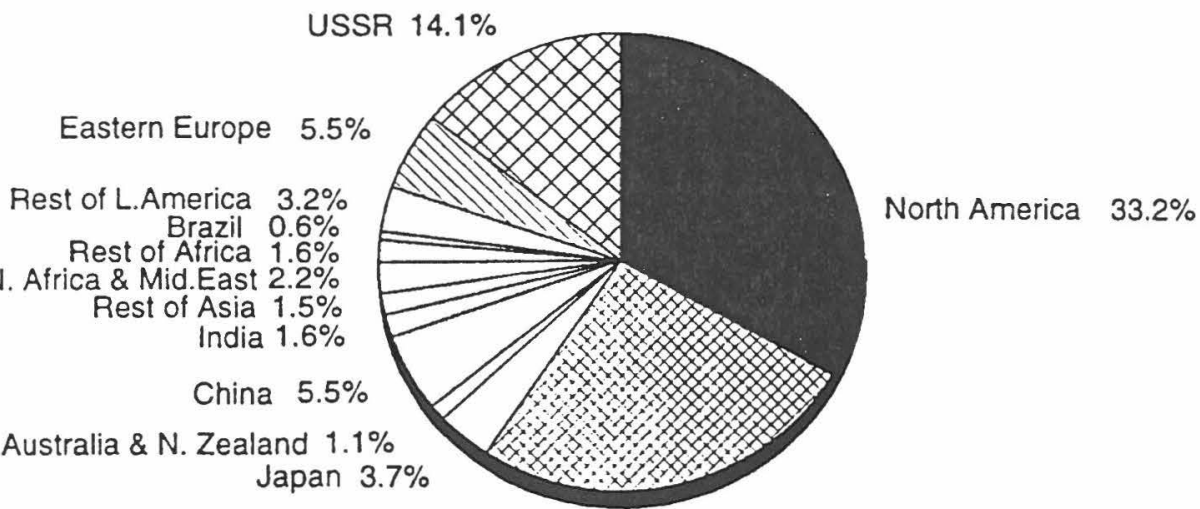

Western Europe $26.1 \%$

Source: Grübler and Nakicenovic, [25] 


\section{Impacts on the atmosphere}

\subsection{Scientific understanding of climate change}

The large variations in the atmosphere on an hourly or daily basis constitute the weather. It is governed by nonlinear 'chaotic' dynamics and is therefore not predictable in the deterministic sense beyond a week or two in the future [34]. A common definition of climate refers to the average weather, usually described in terms of mean and other statistical quantities that measure variability over a period of time and given geographical area [34]. Mean climate is also variable over different temporal and spatial scales. For the longer time-scales of decades to centuries associated with the change of climate due to the effect of enhanced greenhouse warming, the United Nations Framework Convention on Climate Change (FCCC) defines the climate system as the "totality of the atmosphere, hydrosphere, biosphere and geosphere and their interactions" [10]. According to the Second Assessment Report (SAR) of the Intergovernmental Panel on Climate Change (IPCC), often 'climate change' denotes those variations due to human interference while 'climate variations' refers to the natural ones [34].

Atmospheric trace gases help to regulate the temperature regime of the earth. Radiation from the sun is the source of energy which drives the climate system. Incoming solar radiation warms the surface of the earth. Much of this energy is in the visible part of the electromagnetic spectrum. To balance the incoming energy from the sun, the earth itself must radiate on average the same amount of energy back to space by emitting in the infrared part of the spectrum. Part of the re-emitted radiant heat is trapped by trace gases in the atmosphere producing the 'greenhouse effect'.

Figure 4.1 Schematic illustration of the earth's radiative balance, in Watts per $\mathrm{m}^{2}$

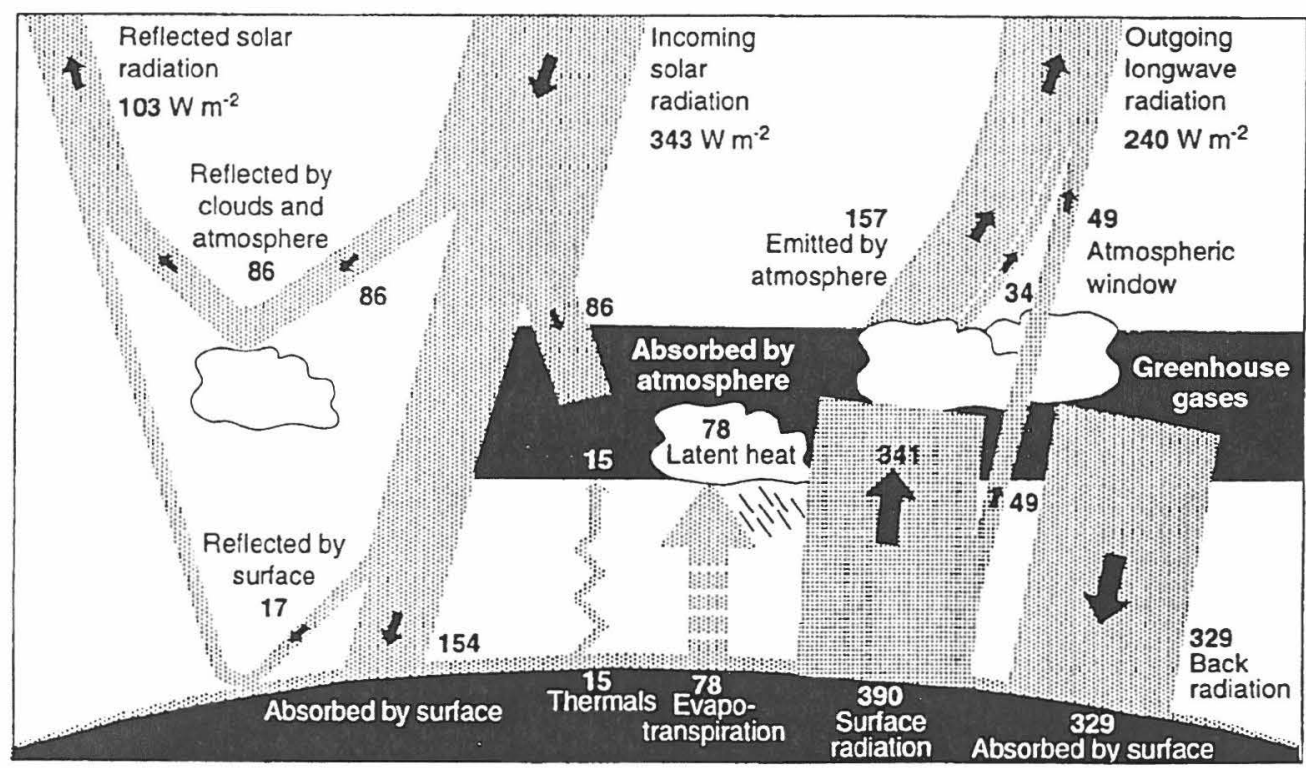

Source: IPCC SAR WG I, [34] 
Most of the atmosphere consists of nitrogen and oxygen which are both transparent to infrared radiation. These two gases constitute $99 \%$ of dry air. The most important infrared absorbing atmospheric gases are water vapour and carbon dioxide which account for $90 \%$ of the natural greenhouse effect. In addition to water vapour and carbon dioxide, other greenhouse gases include methane, nitrous oxide and tropospheric ozone. Figure 4.1 gives a schematic illustration of the earth's radiation and energy balance. Without all of these radiatively active gases that absorb infrared radiation, the surface temperature of the earth would be some 30 degrees Kelvin lower and earth would be inhabitable to life as we know it. This natural greenhouse effect is also involved in governing the surface temperature of the neighbouring plants Venus and Mars.

Since the onset of the Industrial Revolution human activities have not only increased the atmospheric concentrations of naturally occurring greenhouse gases, but have also added new ones. Chlorofluorocarbons (CFCs) also produce a greenhouse effect, although this is offset somewhat by the observed decrease in stratospheric ozone since the 1970s caused principally by CFCs and halons [33]. Human activities have altered the concentrations of greenhouse gases both directly by anthropogenic emissions of carbon dioxide, methane, nitrous oxide and CFCs and indirectly by influencing the complex atmospheric chemistry, including increases in stratospheric water vapour concentrations, depletion of stratospheric ozone and increases of tropospheric ozone concentrations.

Human activities also affect the amount of aerosols in the atmosphere which influences climate in other ways They scatter some incoming solar radiation back to space and thereby cool the earth's surface. A further effect of aerosols is that many of them act as nuclei on which cloud droplets condensate and hence alter the reflection and the absorption of solar radiation by the clouds. Aerosols occur naturally in the atmosphere, e.g., from the eruption of volcanoes or by being blown off the surface of deserts. Sulphur dioxide from coal power plants and biomass burning are the main aerosols resulting from human activities. Previously this was thought to have only local smog and regional acidic precipitation impacts. Recent IPCC findings indicate that some of the net climate warming resulting from the increased concentrations of greenhouse gases is being partially offset by increased concentrations of sulphur dioxide. Because human-made aerosols typically remain in the atmosphere for only a few days they tend to be concentrated near their sources such as industrial regions. However, the aerosol effects do not cancel the global-scale effects of the much longer-lived greenhouse gases and significant climate changes can still result especially once aerosol emissions are effectively controlled to combat local and regional air pollution [34].

Analysis of observations of surface temperature indicates that there has been a global mean warming of 0.3 to 0.6 degrees Kelvin during the last 100 years. The observed trend of a larger increase in minimum than maximum temperatures is apparently linked to associated increases in low clouds and aerosols as well as the enhanced greenhouse effect [34]. In addition, the warmest seven years on observed record have occurred since the early 1980s. The last 15 years have on average probably been warmer than any similar period during the last 600 years [5].

It is also known that the $250 \mathrm{GtC}$ of carbon dioxide emitted due to fossil fuel use and some $120 \mathrm{GtC}$ emitted due to deforestation and biomass burning have increased the atmospheric carbon dioxide content by about $28 \%$ compared to pre-industrial concentration levels. Concentrations of other greenhouse gases such as methane, nitrous oxide and CFCs have also increased markedly. Their total combined effect, without that 
of water vapour, is at present equivalent to an increase in carbon dioxide of almost $50 \%$ [5].

Unfortunately, it is not possible to determine reliably the combined effect of increasing concentrations of greenhouse gases and other effects of human activities on the climate system. Instead, theoretical models of the atmosphere are used to determine the resulting increase in the global mean temperature leading to a range of 0.8 to 2.2 degrees Kelvin calculated warming. The inertia of the climate system compared with the comparatively fast rates of greenhouse gas concentration increases delay in the resulting climate change by 30 to $50 \%$. In addition, the anthropogenic sources of aerosols, principally sulphur dioxide, diminish the theoretical global warming effect by another 20 to $40 \%$. Thus, the observed climate change of 0.3 to 0.6 degrees Kelvin is in the lower part of what would be theoretically expected [5].

Figure 4.2 compares these theoretical estimates of global mean warming due to the increased concentrations of greenhouse gases, with and without the effect of enhanced cooling due to increased emissions of aerosols, with the observed trend in global mean warming. In its recent Synthesis Report about information relevant for the FCCC, the IPCC concludes that this observed global mean temperature increase "is unlikely to be due entirely to natural fluctuations of the climate system, although this explanation cannot be ruled out" [6]. Therefore, scientific evidence is strong that human activities have already caused climate change.

Figure 4.2 Observations in changes in global mean surface temperature from 1860 to the present (curve ending in 1990). Also shown are results of two model calculations to 2050 with (lower curve) and without (upper curve) the impact of sulphur aerosols.

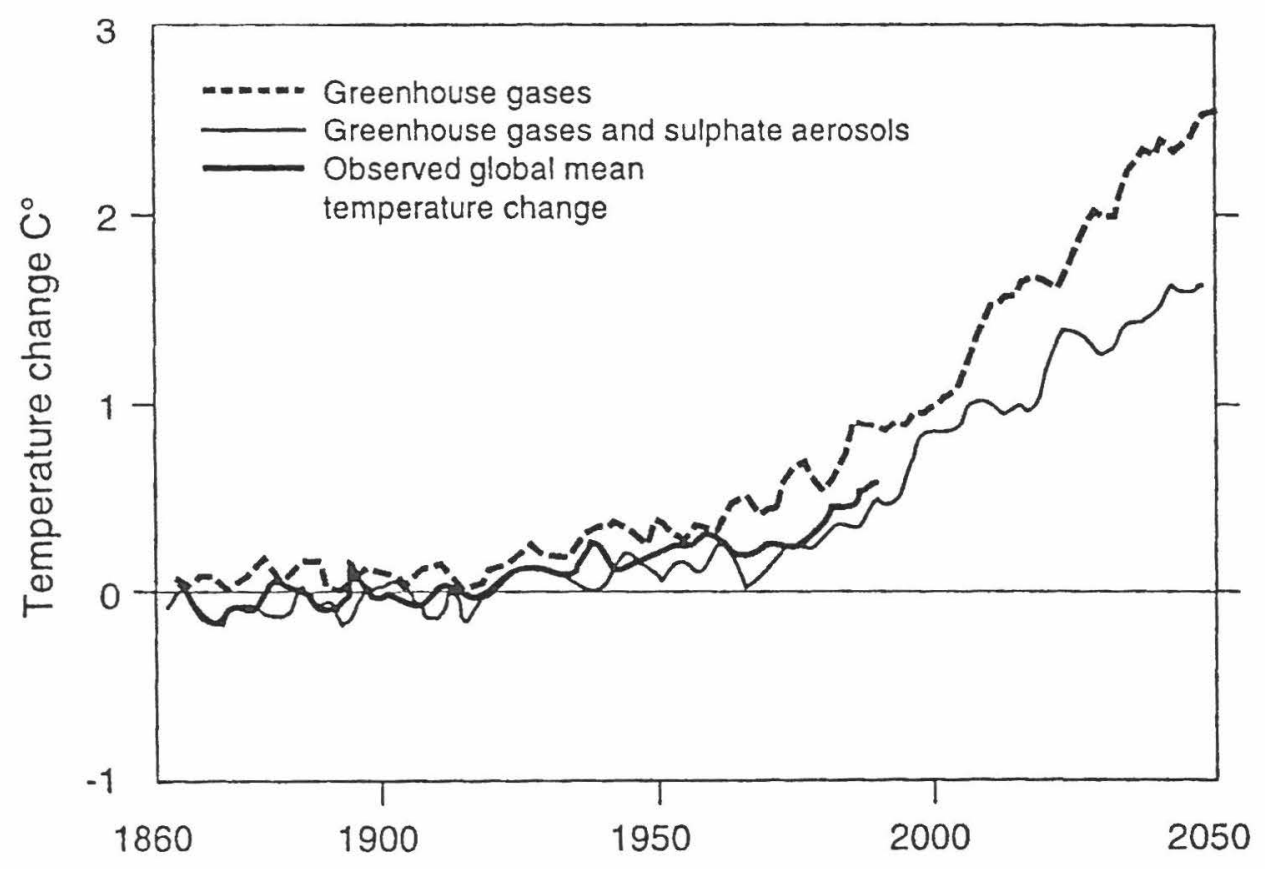

Source: Bolin, [5] 
The FCCC recognizes that human activities may be causing irreversible climate change and that preventive measures should be taken. Its prime objective as expressed in its Article 2 is the "stabilization of greenhouse gas concentrations in the atmosphere at a level that would prevent dangerous anthropogenic interference with the climate system" [10].

Because of the difficulty in predicting the magnitude and geographical distribution of climate change, determination of what might be considered to be 'dangerous' levels of anthropogenic interference with the climate system is primarily a policy rather than a scientific question. People have adapted with varying degrees of success to natural climate variability in the past. Since there is great uncertainty about where, how quickly and how severe adverse impacts of climate change might be and what the potential benefits might be, this analysis will focus on possible strategies to stabilize greenhouse concentrations at alternative levels.

Leaving aside the question of determining 'dangerous' levels of greenhouse gases, other problems are posed by the objective to stabilize their concentrations. It is known that enhanced concentrations of most greenhouse gases remain on average in the atmosphere for 50 to 100 years. An exception is methane with a lifetime of somewhat more than a decade. This has two important implications for sustainable development. First, a significant decrease in greenhouse warming might take half a century or more even after stabilizing greenhouse gas concentrations [5]. Second, the long time scale of climate change and the atmospheric lifetimes of most greenhouse gases are almost matched by the long time scales of replacing human infrastructures, such as the energy system. Even if emissions were immediately stabilized, the long-time constants of the atmosphere system imply a lag of many decades to centuries before stabilization of concentrations is achieved and an equivalent lag before stabilization of temperature occurs.

\subsection{Range of future emissions}

The crucial scientific question in the context of possible climate change is to determine different greenhouse gas emissions scenarios that bracket a sufficiently wide range of alternative atmospheric concentration levels. By doing so one can explicitly specify alternative energy development paths that correspond to different concentration levels and thus aid the policy process of identifying stabilization of concentrations at a "level that would prevent dangerous interference with the climate system" [10].

Figure 4.3 shows historical carbon dioxide emissions levels and a wide range of alternative future trajectories from the literature. The lower ones lead to stabilization of concentrations levels, while the high emission paths imply a continuous increase of concentrations beyond the end of the next century. A number of alternative stabilization levels and emission pathways leading to them are illustrated including 450 parts per million by volume (ppmv), 550 ppmv (doubling of pre-industrial concentration), and ranging to quite high concentrations up to $750 \mathrm{ppmv}$. The alternative scenarios in Figure 4.3 have in common a doubling of the global population to about 12 billion by the end of the next century. For simplicity, only two sets of scenarios are shown. 
Figure 4.3 Historical and range of future emission paths of energy related carbon emissions based on two sets of representative scenarios with a medium population projection from the IPCC (IS92 series) and IIASA-WEC (A1 to C). Also shown are illustrative emission paths that would lead to a long-term stabilization of atmospheric concentrations at levels of 450, 550, 650 and 750 ppmv respectively.

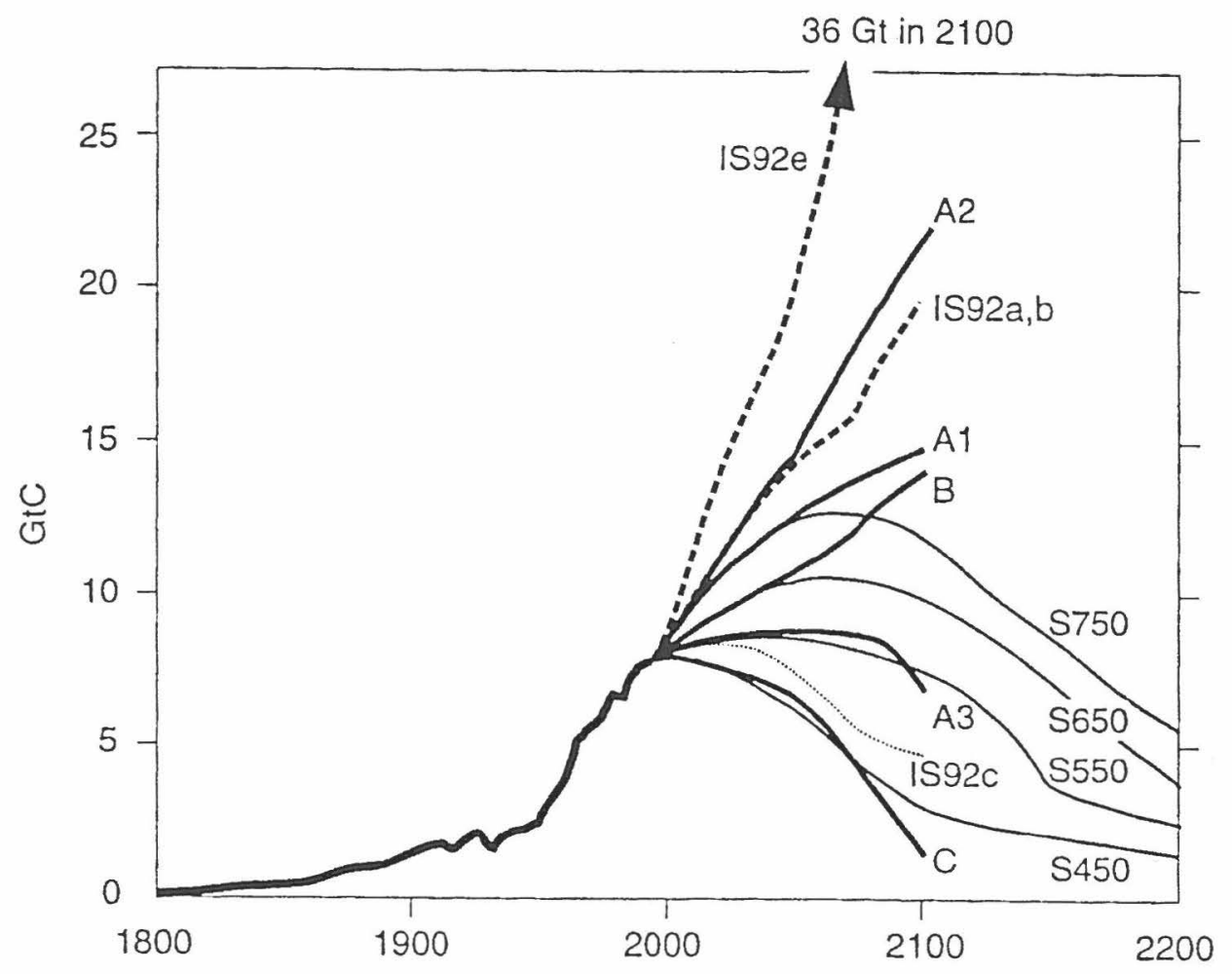

Source: IPCC SAR WG I, [34] and IIASA-WEC, [35]

One is based on the scenarios developed by IPCC from a whole range of varying assumptions including alternative future population levels. Shown are the central and the highest scenarios [36] that share the same population assumption. For comparison the dotted lines in Figure 4.3 show the lowest IPCC scenario (IS92c). This scenario leads to stabilization of concentrations at a relatively low level of 450 ppmv because it is based on modest economic growth and an insignificant increase in world population to 6.3 billion by 2100 . The IS 92 set of IPCC scenarios is considered as one of the standard references in the literature.

The other set of scenarios stems from a joint study by the International Institute for Applied Systems Analysis (IIASA) and the World Energy Council (WEC) on long-term global energy perspectives $[12,35]$. The set includes six scenarios based on a common intermediate population projection. The six scenarios range from very low emission levels leading to stabilization at $450 \mathrm{ppmv}$ to very high emission paths that imply continuing increases in concentrations beyond 2100 . The three scenarios labelled A1, A2 and $\mathrm{A} 3$ are of particular interest because they are all based on the same high levels of economic growth and energy consumption in the world. Alternative structures of the 
economy and energy system, however, lead to radically different emissions. In scenario A 1, for example, which is based on increasing shares of natural gas, emissions reach 15 $\mathrm{GtC}$ in 2100 . In the coal-intensive $\mathrm{A} 2$ scenario, they reach $22 \mathrm{GtC}$. In scenario A3, which is based on a larger contribution of nuclear and renewable energy sources, emissions reach only $7 \mathrm{GtC}$, which is comparable to current emissions levels. This last scenario is consistent with concentration stabilization at $550 \mathrm{ppmv}$ despite high levels of economic and energy growth. It illustrates that sustainable energy development need not be associated with austerity measures. The emissions in scenario B are comparable to those of A3 scenario by 2050 but then increase to twice the level of A3 by 2100 due to a lack of significant structural changes in the energy system and a continuing reliance on carbonintensive sources of energy.

The two $\mathrm{C}$ scenarios are a special case because they were constructed to stabilize emissions at current levels by the mid- $21^{\text {st }}$ century in order to meet an emissions ceiling of $2 \mathrm{GtC}$ by 2100 [37]. Such an emission profile would lead to stabilization of concentrations at the comparatively low level of $450 \mathrm{ppmv}$. This assumes a new regime of global environmental governance, including full implementation of the FCCC with ensuing emission control protocols and aggressive international cooperation centred around environmental protection and international economic equity. Stabilization at 450 ppmv can be considered to ensure sustainability from the point of view of possible climate change. Few would argue that 450 ppmv is a 'dangerously' high concentration level for future generations. In contract to the IPCC IS92c scenario that achieved stabilization via extremely low (exogenous) demographic and economic growth assumptions, this scenario achieves stabilization at 450 ppmv levels due to deliberate policy action in a world of 12 billion people and with a significant reduction in current economic disparities between world regions.

The scenarios shown in Figure 4.3 span a very wide range of possible future carbon dioxide emissions, from two to $36 \mathrm{GtC}$ by 2100 , from a stabilization of concentrations at a low level of 450 ppmv to a continuous increase beyond a doubling of current concentrations that is reached as early as the 2070s. This range includes the majority of emission scenarios available in the literature [31].

The analysis of alternative scenarios indicates that their cumulative emissions over time are the single most important characteristic for determining the level of future greenhouse gas concentrations. This is an important and a robust result [5]. It means that the shape of the emissions paths is not that crucial as long as the total emissions are not changed by a given period. For example, scenarios that foresee a more rapid increase in emissions to begin with would have to have a faster decline later on to achieve the same level of stabilization. What is common to all of the paths that lead to stabilization is that their emissions must fall to $3 \mathrm{GtC}$ or less per year by the time stabilization is achieved. This emissions level corresponds to the capacity of natural sinks to absorb additional carbon dioxide emitted to the atmosphere.

An overall result of this analysis is that scenarios that lead to stabilization at levels of about 450 ppmv have cumulative emissions in the range of about $600 \mathrm{GtC}$ by 2100 . Scenarios with cumulative emissions of more that $1,000 \mathrm{GtC}$ by 2100 , result in concentrations of more than $550 \mathrm{ppmv}$, or more than double the pre-industrial levels. Scenarios in excess of $1,000 \mathrm{GtC}$ cumulative emissions by 2100 lead to continuing increases in concentration levels extending beyond that period. In comparison, the current atmospheric carbon dioxide content is about $760 \mathrm{GtC}$. Therefore, sustainable energy development from the point of view of the current understanding of possible climate 
change implies cumulative carbon dioxide emissions by 2100 in the range of less than $1,000 \mathrm{GtC}$.

Most of the scenarios that lead to emissions in this lower range of the scale involve active measures to change the structure of future energy systems so as to lead to lower environmental impacts and at the same time providing sufficient energy for economic development in the world. As an illustration that such transitions to lower future greenhouse gas emissions paths should not be considered to occur automatically, suffice it to say that the currently known reserves of conventional fossil energy in the world are estimated at 3,000 to 5,000 $\mathrm{GtC}$, an amount that by far exceeds the above cumulative emissions levels. The total occurrences of fossil deposits in the earth's crust that might be in theory available to humanity as a 'carbon endowment' are estimated to be in the range of $25,000 \mathrm{GtC}$ [34].

It has already been mentioned that the historical responsibility for the current atmospheric carbon dioxide concentrations beyond the pre-industrial levels rests with the now developed parts of the world. They are responsible for more than $80 \%$ of this increase. In the future, most scenarios indicate that the share of global emissions from the currently developing countries would increase as they industrialize and their levels of affluence reach those now prevailing in the developed parts of the world. By the end of the next century, the now developing countries may account for anywhere between 60 and more than $80 \%$ of global greenhouse gas emissions. This also means that global emission reduction strategies must take into account the future energy perspectives of the developing countries. It can be argued that this puts an additional responsibility on the now developed countries to set an example and develop the required technologies, institutions and policy measures to achieve emissions reductions. These countries not only have the required know-how and experience but also possess the majority of the financial and institutional resources needed for developing the necessary preconditions for sustainable energy development.

\section{Options for mitigation and adaptation}

What are the options for the protection of the atmosphere? Mitigation and adaptation options and policy instruments for their implementation, need to be varied and comprehensive in view of the multitude of pollutants, the pervasiveness of emissions across a wide range of human activities, and the time scales involved in possible climate changes. The most obvious option to mitigate against undesirable impacts of unabated emissions is emission reduction.

Modern societies depend on elaborate and complex systems for converting energy from less to more desirable forms. Losses occur in all these conversion processes and emissions of various pollutants are released into the atmosphere. The overall emissions released by the energy system depend on the structure and efficiencies of energy supply, conversion and end use. Emissions reductions can be achieved by efficiency improvements, fuel switching and structural change to cleaner energy forms and by technological means of reducing pollutants from large point sources. Two further mitigation options are the enhancement of greenhouse gas sinks and adaptation measures. These options and their mitigation and adaptation potential are assessed below. The final 
part of this section (5.7) then reviews some special circumstances in different world regions.

\subsection{Efficiency improvement potentials}

Efficiency improvements constitute the most generic mitigation options. A more efficient provision of energy services not only reduces the amount of primary energy required but, in contrast to other options with single objectives of reducing emissions of a particular greenhouse gas, efficiency improvements also reduce adverse environmental impacts across all pollutants, resource use and energy costs. It is also the option that is generally considered to have the largest mitigation potential. However, although efficiency is important it is not the only determinant of all energy systems performance. Other determinants include, for example, the availability and controllability of energy flows, capital and operating costs, etc. Energy can be used more or less efficiently; this sometimes depends on technical factors or the capacity utilization, but more often it is a question of economic and social choice, i.e., the question of lifestyles and, consequently, the kinds of energy services that are demanded and provided.

Figure 5.1 Global energy efficiency in 1990 (a), top, and efficiencies obtainable through the application of best available technologies (b), bottom; conversion efficiencies as percentages of primary energy

(a)

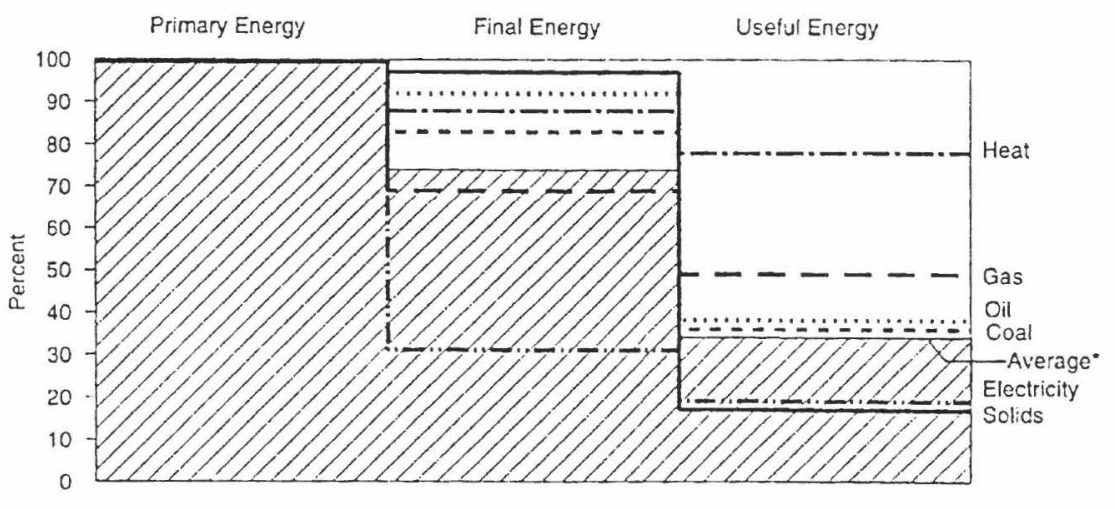

- Vector specific efficiencies exclude cogeneration; average includes district heat and ccgeneration

(b)

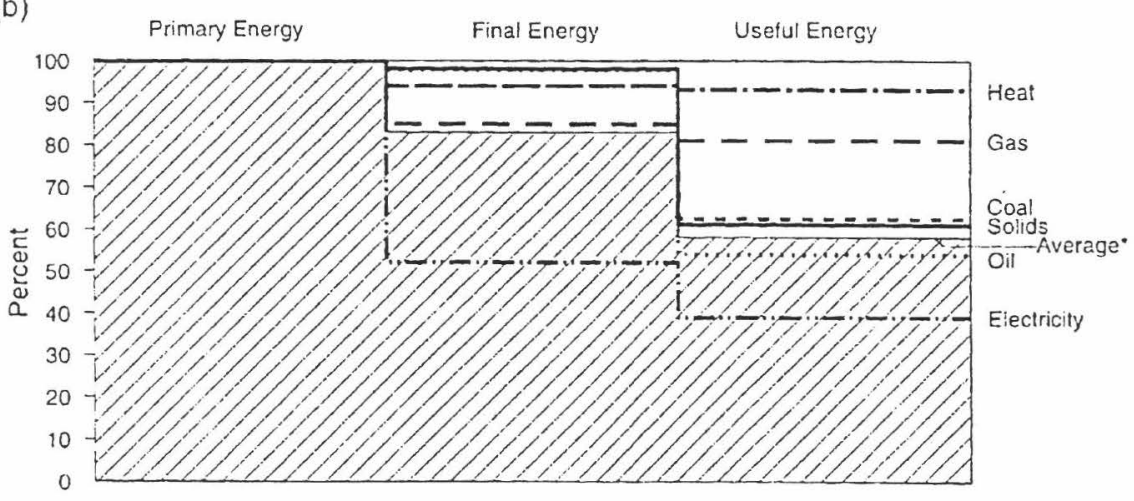

Source: Nakicenovic et al., [38] 
Energy efficiency is usually measured as the ratio of energy output to input. Measured this way, significant energy efficiency improvements have been achieved for almost all types of energy conversion facilities. For example, dramatic improvements in fuel conversion efficiencies in electricity generation have been achieved during this century. At the turn of the century the prevailing efficiency of electricity generation was about $5 \%$, whereas today the average efficiency in OECD countries is about $36 \%$ and the best combined-cycle natural gas-fired power plants can achieve more than $50 \%$ efficiency. To evaluate how large the improvement opportunities are, if, for example, the most efficient devices and systems are used, first the overall efficiency of the energy system has to be determined. This means calculating the aggregate efficiency of different energy chains (composed of many individual energy conversion devices) and then determining the weighted average efficiency of the entire energy system from primary to final and useful energy. The results from such an analysis are reported in Figure 5.1.

Figure 5.1 shows that the average aggregate efficiency of energy transformation from primary to useful forms at the global level is about $34 \%$. The highest efficiencies are in the conversion of fuels from primary to secondary energy forms. Refinery efficiencies are about $90 \%$ and, on average, the conversion, transport and distribution of energy has rather low losses with efficiencies ranging from about 60 to almost $90 \%$.

Overall, the primary to final energy conversion processes, i.e. the domain of the energy sector proper, are quite efficient with a global average of about $74 \%$. In comparison, the final to useful energy conversion efficiency, the domain of the energy consumers, is very low with about $46 \%$ at the global level. In general, natural gas and electricity have the highest end-use efficiencies compared with the lowest primary to final conversion rates. The lowest end-use efficiencies are those of biomass with about $17 \%$, mainly as a result of the predominance of traditional end-use conversion devices in developing countries.

As stated above, the overall primary to useful energy efficiencies are $34 \%$ at the global level. A similar analysis for different world regions [38] gives corresponding numbers of $22 \%$ in the developing countries and $42 \%$ in the economies in transition. The latter result may at first sight be surprising. Generally, energy technologies of economies in transition are rather inefficient, especially when compared with the standards prevailing in the market economies of the OECD. All individual primary to useful energy chains are more efficient in the market than in the transition economies. The reason for the reverse situation with the overall aggregate systems efficiency is that the structure of the energy systems in the economies in transition favours collective consumption and thus also end-use efficiency. People travel by public transport rather than private cars and heat their homes using cogenerated heat rather than individual oil burners. Thus, while cars and buses are more fuel efficient in the market economies, travelling by bus in the economies in transition is more energy efficient than riding in a car in any of the OECD countries.

The most important overall result is that energy end use is the least efficient part of all energy systems and it is in this area that improvements would bring the greatest benefits. It also shows that even the most efficient technologies may not be sufficient to offset the energy-intensive lifestyles prevailing in very affluent market economies.

The largest relative efficiency improvement potential exists in the developing countries, followed by the transitional economies, because of the prevalence of traditional economic patterns and inefficient energy end use technologies in these areas. Outdated 
technological vintages and, more generally, chronic capital shortages, limit the replacement of obsolete technologies and investment into new, more energy-efficient ones. The largest absolute efficiency improvement potential remains in the industrialized countries of the OECD, despite their generally more modern and energy efficient capital stock. This is simply because the absolute level of energy use in the OECD countries accounts for 4.4 Gtoe or half of global primary energy use. The application of today's efficiency levels of the market economies of the OECD to provide useful energy for the rest of the world would reduce the global primary energy requirements by $17 \%$, from 9 to $7.5 \mathrm{Gtoe}$, and would also lead to a similar reduction in carbon dioxide emissions.

An instantaneous (hypothetical) replacement of the current global energy system by the best and most energy efficient technologies available would result in an overall primary to useful energy efficiency improvement of $60 \%$, i.e., from $34 \%$ to $55 \%$ (Figure 5.1). In other words, total primary energy requirements in this hypothetical scenario would decrease from about 9 to about 5.5 Gtoe and, assuming no structural changes in the energy system, global carbon emissions would also be reduced correspondingly, from 6 to $3.6 \mathrm{GtC}$.

This assessment of the current to near-term energy efficiency improvement potential is corroborated by other studies [22]. This impressive efficiency improvement potential is, however, merely a technical potential. It ignores costs, the time it might take before new more energy-efficient technologies can be introduced, as well as the numerous institutional and social changes that would be necessary for their implementation. Considering these and, in particular, financial constraints, the technical potential reduces to a realizable efficiency improvement potential in the range of between ten to $30 \%$ of current energy use worldwide and is of a similar magnitude over reference baseline scenarios over the next two to three decades. This represents the economic potential of energy efficiency improvements: reductions in energy use that can be achieved at no additional cost and, in most cases, at significant cost savings to society (but not necessarily to individual consumers).

The energy efficiency improvement potentials identified above represent current to near-term potentials. They are, however, inadequate as an assessment of the ultimate energy efficiency potential. A more appropriate measure for such an assessment is to determine the theoretical minimum energy requirements for a given task, as defined by the second law of thermodynamics (so-called exergy analysis). The distinction between energy and exergy efficiency is important because it allows the determination of the ultimate potential of efficiency improvements. The second law of thermodynamics defines a quantity called available work or exergy. It can be used instead of energy to define an alternative efficiency measure: the ratio of the theoretical minimum amount of available work or exergy needed to perform a particular task to actual available work or exergy consumed by a particular device or a system to perform the same task.

A number of studies have analysed the efficiency of current energy systems using second-law or exergy analysis. All indicate that primary to service efficiencies are as low as a few percent. AIP [39] and later Oliver et al. [40] were among the first to give a detailed assessment of end-use exergy efficiencies, including service efficiencies. Ayres [41] calculated an overall primary exergy to service efficiency of $2.5 \%$ for the USA. Other estimates for individual countries range up to 15 to $23 \%$ [22]. Estimates of global and regional primary-to-service exergy efficiencies vary from ten to as low as a few percent $[42,38]$. 
The results indicate that the theoretical potential for efficiency improvements is very large, ranging between a factor of five to 20 . Current energy systems are nowhere close to the minimum energy requirements suggested by the second law of thermodynamics. This means that the current and future demand for energy services could be satisfied with as little as five to $20 \%$ of current energy use. These estimates do not involve changes of energy tasks or lifestyles. Allowing for such changes would make the efficiency improvement potential even higher. For example, such a change would be the satisfaction of mobility needs by public transport or by walking instead of a private car. Such an analysis indicates thermodynamically defined efficiency improvement potentials. The actual realization of these potentials depends on numerous factors and constraints, among others, technology development, transfer and diffusion, capital availability and appropriate economic and institutional incentives, including removal of barriers and distortionary subsidies. However, what can already be achieved with current best practice technologies and devices available on the market remains significant. The realization of this potential, however, presupposes the availability of financing and the existence of the appropriate incentives.

\subsection{Fuel switching and substitution}

Fuel switching is an option that involves structural shifts from emissions-intensive fossil fuels to cleaner ones. For instance, switching from coal to natural gas reduces carbon dioxide emissions and, at the same time, reduces particulates and sulphur dioxide emissions that constitute important local and regional air pollutants. About $43 \%$ of current energy-related carbon dioxide emissions originate from coal, about $39 \%$ from oil and $18 \%$ from natural gas [22]. Per unit energy, the carbon dioxide emissions of natural gas are only half as large as those of coal and three-quarters those of oil. Fuel switching, e.g., from coal to gas in electricity generation, therefore represents a considerable emission reduction potential. Past structural changes in energy supply, from coal dominated energy systems towards oil and, more recently, natural gas, have resulted in a continuous 'decarbonization' of the energy system. The global carbon dioxide emissions decreased per unit of primary energy used in the world as a consequence of structural changes in the energy system (cf. Section 3 above).

The ultimate potential of emission reduction via fuel substitution is difficult to determine. Regional resource availability, trade possibilities, price differentials and geopolitical considerations may limit fuel substitution possibilities, e.g., of domestically produced coal by imported natural gas. The near term potential of fuel substitution is rather limited because the development of alternative energy supply sources, conversion facilities, end-use devices and the corresponding changes in infrastructures all take considerable time.

Conversely, over longer time periods, the emission reduction potentials increase substantially. Illustrative scenarios, e.g., the 'methane economy' scenario developed by Ausubel et al. [43] indicate that duel substitution, in particular favouring natural gas and in conjunction with the enhanced penetration of zero-carbon options such as nuclear or renewables, could reduce emissions substantially compared to coal intensive 'business as usual' scenarios. These findings are corroborated by the IIASA-WEC long-term energy scenarios [12,35]. Carbon emissions by the end of the 21 st century of a scenario relying on natural gas as a transitional fuel in conjunction with significant market penetration of 
cost-effective nuclear and renewable energy sources, could amount to only $7 \mathrm{GtC}$, compared to $22 \mathrm{GtC}$ for a similar, but coal and synfuels intensive, scenario. For both scenarios, global energy demand is projected to be five times higher than today. Figure 5.2 illustrates the more near to medium-term potential of fuel substitution. Taking the coal intensive IS92a IPCC scenario [36] as a baseline, it illustrates the impact on carbon emissions of replacing all global coal consumption in the scenario by oil or natural gas respectively over the next 40 years [22]. This hypothetical calculation illustrates the magnitude of emission reductions via fuel switching among fossil fuels only. Shifting all coal use in the scenario to natural gas would reduce emissions by the year 2035 from over $7 \mathrm{GtC}$ to some $4 \mathrm{GtC}$, i.e. by over $40 \%$.

Figure 5.2 An illustrative example of carbon dioxide emissions reduction through fossil fuel switching and substitution. Annual carbon emissions from coal in the (coal intensive) IS92a IPCC reference scenario and the corresponding emissions if oil and gas respectively would replace coal (in $\mathrm{GtC}$ )

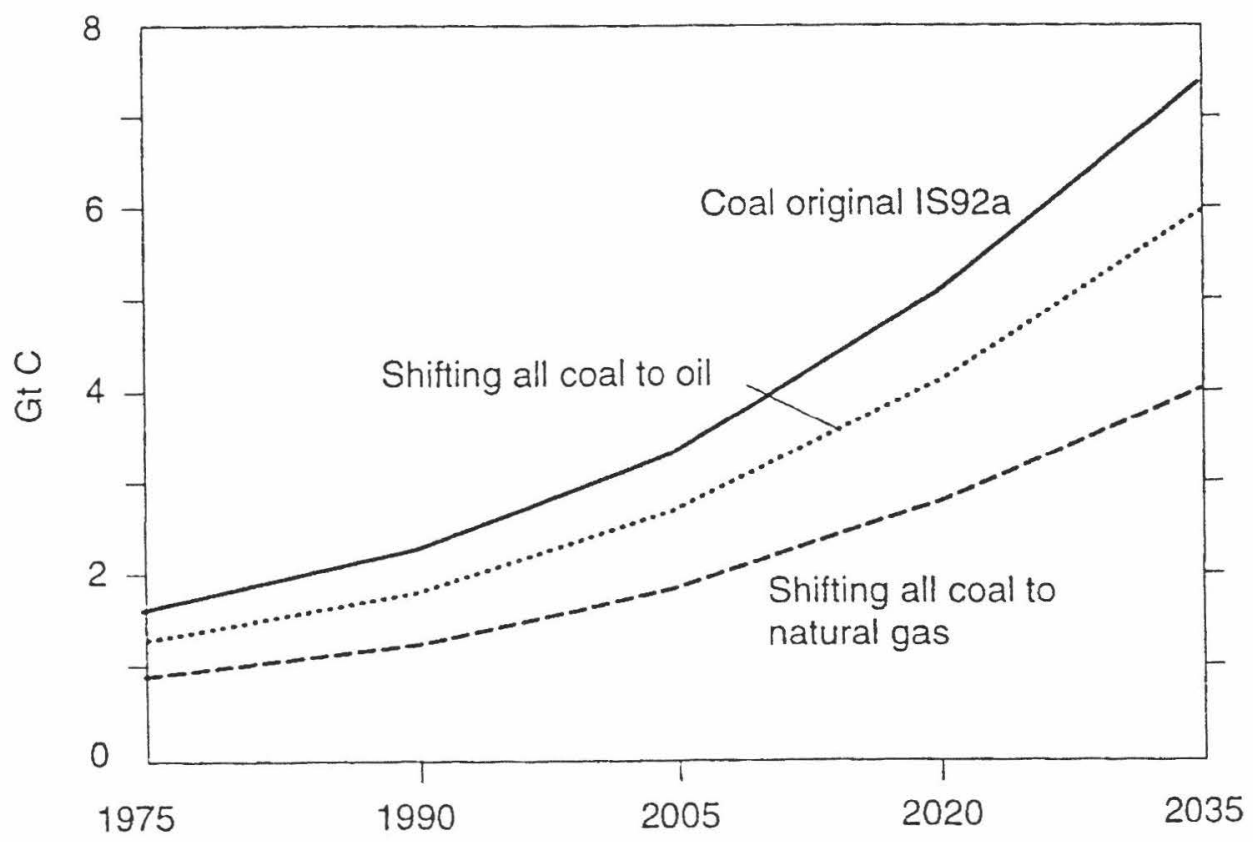

Source: IPCC SAR WG II, [22]

The investments embodied in existing energy infrastructures and regional resource availabilities constrain the emissions reduction potentials of fuel substitution. In view of such constraints, this option would be more effective if it were combined with vigorous efficiency improvement efforts and ultimately with carbon scrubbing and disposal.

\subsection{Structural change to renewables and nuclear}

Structural change is an option that involves transformation of the energy system from the current predominance of fossil fuels towards carbon-free energy sources such as solar and nuclear, or towards sources that are carbon-neutral with respect to the atmosphere, such 
as the sustainable use of biomass [44]. In the latter case, the atmospheric carbon dioxide released during combustion is absorbed during regrowth, hence its characterization as a carbon-neutral energy source.

The emissions reduction potentials of carbon-free and neutral energy sources is large indeed and in the long run may exceed that of efficiency improvements. Studies indicate that over very long time scales (of one century) it would be possible to restructure the global energy system entirely away from the use of fossil fuels, especially when combined with vigorous conservation and energy efficiency improvement efforts $[45,12,22]$. In practice many factors limit the mitigation potential of a structural change to carbon-free and carbon-neutral energy sources such as high costs, availability of technology and capital and other resource constraints. For example, competing land uses between agriculture and 'energy plantations' can limit the global mitigation potential of biomass.

One of the most systematic analyses of the long-term potentials of renewables and nuclear energy was carried out for the World Energy Council's 1995 Congress in Tokyo [12]. In contrast to other studies that usually focus on one single energy demand scenario, a range of demand scenarios was explored with respect to alternative energy supply options. The study also considered international trade, technology availability and costs, as well as other possible constraints for the penetration of renewable and nuclear energy. Hence the resulting supply potentials identified represent a detailed techno-economic assessment rather than a mere illustration of technical or theoretical supply potentials.

Figure 5.3 Minimum and maximum annual contribution of renewables, biomass and nuclear to global energy supply, from IIASA-WEC scenarios (in Gtoe) [12,35]

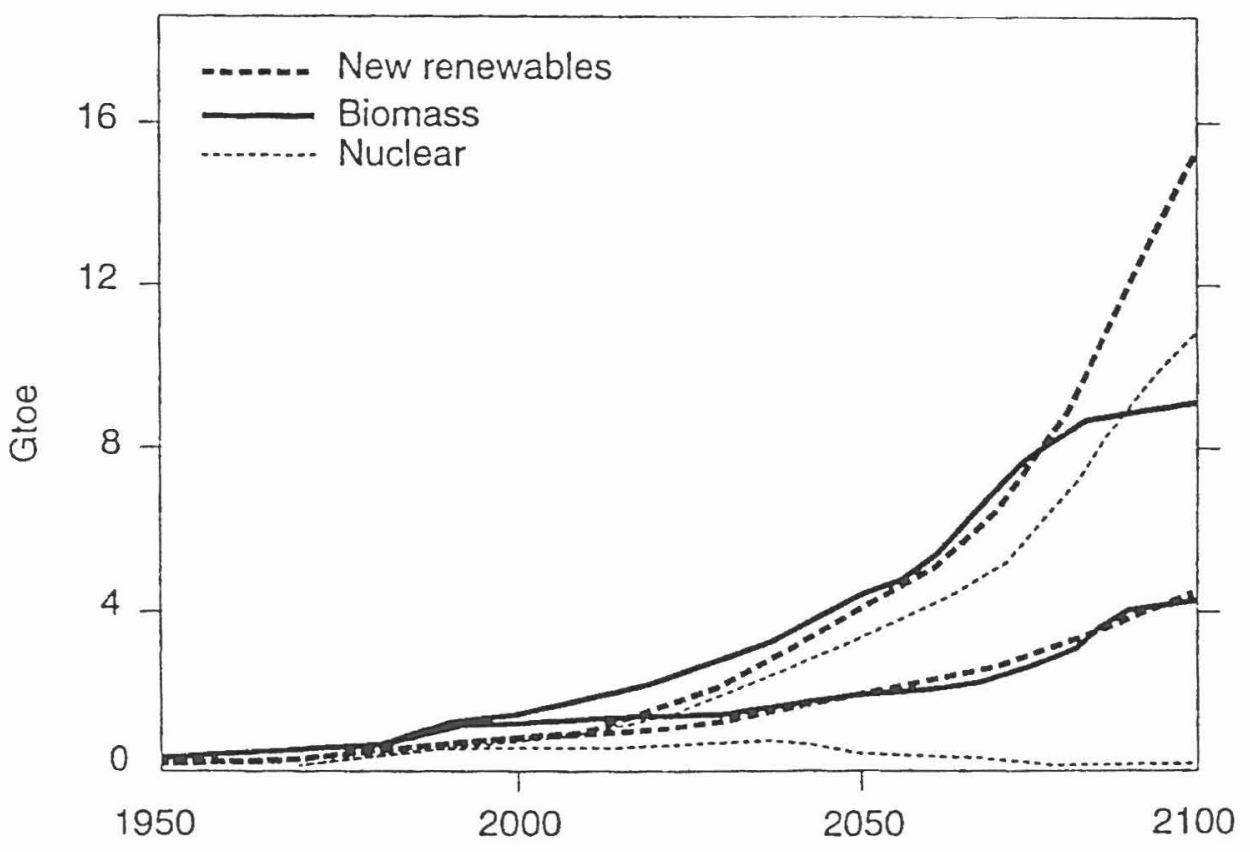

Source: IIASA-WEC, [12,35] 
The resulting minima and maxima of all alternative contribution profiles for all carbonfree and neutral options are presented in Figure 5.3. Three sets of minima and maxima are shown for new renewables (wind, solar or geothermal), sustainable biomass use and for nuclear energy. The range between the two extremes is the largest for nuclear energy due to the current uncertainties regarding proliferation, waste disposal and social acceptability issues. Nuclear energy ranges from a complete moratorium by the end of the 21 st century to a contribution of $10 \mathrm{Gtoe}$, thus exceeding total current world energy use. For biomass the range extends from 4 to 9 Gtoe and for other renewables from 4 to 14 Gtoe by the end of the 21 st century. The carbon dioxide emissions mitigation potential of these energy sources depends on the structure of the fossil fuel mix; it depends primarily on whether they are substituting coal, oil or natural gas. The potentials are the highest when coal is substituted: worldwide by 2100 , they are about $5 \mathrm{GtC}$ in the case of new renewables and biomass minima, respectively (but zero for a nuclear moratorium); about $10 \mathrm{GtC}$ for biomass and nuclear maxima, respectively, and finally about $15 \mathrm{GtC}$ for the new renewables maximum. In the case of natural gas substitution, the corresponding global mitigation potentials are somewhat smaller with 3,5 and $9 \mathrm{GtC}$, respectively.

The realization of the long-term mitigation potential of these options, however, requires near-term concerted research and development efforts. Technology demonstrations in initial niche markets to facilitate technological learning and cost reductions are required in order that these options become competitive with fossil fuels, particularly in the case of renewables and biomass. In the case of nuclear energy, acceptable responses need to be found to concerns about safety, waste disposal and proliferation issues. Hence, structural change would be also a more effective option if it were combined with vigorous energy efficiency improvement efforts.

\subsection{Control of large point sources}

Control of large point sources is an option that focuses primarily on emissions reduction from power plants and large energy conversion facilities, similar to the current technologies for reducing emissions of particulates matter, sulphur dioxide and nitrogen oxides.

The theoretical emissions reduction potential of this option is substantial. Possible control measures include scrubbers for carbon dioxide removal that are applicable mostly to large fossil power plants and some industrial processes. In most cases the technological feasibility of emission control has been demonstrated although costs are still prohibitive in many cases.

For example, the recovery of methane from coal mines is practiced widely and is usually cost-effective since recovered gas can be used for energy purposes. Stabilization of atmospheric methane concentrations would require a reduction of current global anthropogenic emissions by $5 \%$ (or about $22 \mathrm{TgCH}_{4}$ ). Such a reduction would correspond to about a quarter of the methane released by the energy sector [22,34]. Current estimates indicate that the methane emission reduction potential at negative or low costs amounts to $10 \%$ of anthropogenic emissions [22]. The largest reduction potentials are in waste management and agriculture. That is, stabilization of current atmospheric methane concentrations is feasible in the near term by implementing a part of the cost-effective options.

In contrast, carbon dioxide scrubbing from flue gases is still prohibitive economically as a large-scale mitigation strategy. Carbon removal by scrubbing is technically feasible 
and is practiced in a number of plants that recover carbon dioxide for use in the food industry. The feasibility of scrubbing and subsequent disposal of carbon dioxide still remains to be demonstrated on a large scale. There are three main scrubbing processes: chemical and physical absorption, cryogenic distillation and membrane separation. One of the problems is that the present carbon removal methods that involve (chemical absorption by) amine scrubbers have high capital and operating costs and result in a substantial reduction of power plant efficiencies in the range of $25 \%$. Typical scrubbing costs are in the region of US\$ 150 per ton carbon removed and for some processes can exceed US\$ 500 per ton carbon [38,22]. As a result, electricity generating costs could easily double, indicating the substantial economic cost of this mitigation option.

In addition, the issue of storing gigantic quantities of sequestered carbon dioxide for potentially thousands of years remains unresolved. Permanent storage of billions of tons of carbon is a daunting task. Potential carbon dioxide utilization, disposal and storage options include enhanced oil recovery, storage in depleted natural gas fields and other underground reservoirs, chemical feedstocks and other basic materials and, finally, also disposal in the deep ocean. Some of these options have more limited potentials such as the utilization of chemical feedstocks and enhanced oil recovery. All of them involve unresolved issues of possible long-term leakages, often unknown disposal costs and, perhaps most importantly, as yet unknown environmental impacts. Disposal in the deep ocean has one of the largest potentials since the oceans currently store more than 40,000 billion tons of carbon compared to six billion tons of global emissions from energy use. Among the major outstanding uncertainties are the possible ecological effects of higher concentrations of carbon dioxide in the oceans and their effects on local chemistry in the vicinity of storage sites [38].

\subsection{Enhancement of natural sinks}

Enhancement of sinks is limited as a mitigation option to those greenhouse gases that are absorbed by natural sinks, as is the case with carbon dioxide. Large amounts of carbon dioxide are continuously removed from the atmosphere through natural processes such as photosynthesis, weathering of rocks and absorption by the oceans. However, the rising concentration of greenhouse gases indicates that, due to anthropogenic activities, emissions have exceeded the absorptive capacity of the sinks. The enhancement of sinks can be achieved by a variety of measures. Potential options include so-called 'geoengineering' options such as deep-ocean storage, weathering of rocks, or 'ironfertilization' of ocean plankton productivity. It is not known whether these options are feasible and whether they are associated with other significant environmental impacts. The most important options include the preservation and the enhancement of the terrestrial carbon sink. Vegetation is the largest terrestrial carbon sink. It absorbs carbon dioxide by photosynthesis. The obvious measure is to halt global deforestation and enhance vegetation growth.

Estimates of carbon releases through land-use changes during the 1980 s, including deforestation, indicate a net annual flux of carbon to the atmosphere of between 0.6 and $2.8 \mathrm{GtC}$ (with a median value of $1.6 \mathrm{GtC}$; [34]). This compares to about $6 \mathrm{GtC}$ of fossilenergy related emissions. In addition to carbon dioxide emissions, deforestation and its associated biomass burning release other gases with a direct or indirect greenhouse effect, most notably methane, nitrous oxides and carbon monoxide. 
Illustrative scenarios indicate that, in the absence of policy measures, deforestation rates could significantly increase future greenhouse gas emissions (for a review see Alcamo et al., [31]). Annual carbon dioxide emissions could be in the range of 3 to $5 \mathrm{GtC}$ during the next century leading to an eventual destruction of the majority of the world's forests including practical extinction in the tropical regions. In a worst-case scenario, up to $340 \mathrm{GtC}$ might be released into the atmosphere over the next century from deforestation and land-use changes. In comparison, the current atmospheric carbon content is about $760 \mathrm{GtC}$.

In contrast, between 100 and $150 \mathrm{GtC}$ could be sequestered from the atmosphere over the same time period through a dedicated global afforestation program. A number of studies have assessed the potential of carbon sequestration through global afforestation programs. Estimates indicate that over a period of 50 to 100 years between 1 and $2 \mathrm{GtC}$ could be sequestered annually. For instance, Nilsson [46] and Nilsson and Schopfhauser [47] estimate a sequestration potential of $1.6 \mathrm{GtC}$ per year through a 'global plantation' program, including existing local reforestation schemes. The direct costs for such a program are estimated to amount to up to US $\$ 500$ billion for a cumulative removal of some $120 \mathrm{GtC}$ (although infrastructural, educational, land rights and other indirect costs might increase this figure by a factor of two to three). The resulting average sequestration costs would be about US\$ 4 per ton of carbon removed. This figure compares extremely favourably with the more capital-intensive mitigation options of the energy sector. The only exceptions are the low to negative costs associated with energy efficiency improvements. However, it has to be emphasized that afforestation costs can vary significantly between regions. Nilsson [46] identifies cost differences of up to a factor 30 between different regions, with costs in more thinly populated, tropical regions being on the lower extreme, and costs in high labour-cost, northern-latitude countries being on the high extreme of the afforestation cost range. There would also be significant impacts on world timber markets. This indicates that regionally different strategies must be found to balance the impacts of a global carbon sequestration program. For example, wood use could be encouraged as a replacement for fossil fuels and as a basic material.

Even if such a global afforestation program became feasible politically, institutionally and economically, several decades would pass before the maximum sequestration rates through forest regrowth could be achieved. From the perspective of the protection of the atmosphere and the carbon cycle, therefore, slowing down and eventually halting deforestation appears a more immediate priority for the enhancement of sinks.

\subsection{Adaptation measures}

Adaptation options constitute a large number of specific, preventive measures to enable people and natural ecosystems to adapt to possible climate change. This option could be employed in conjunction with mitigation measures, or as a last resort in the case of unavoidable and significant climate change.

Adaptation measures are discussed here mainly for the sake of completeness, as they are not measures to protect the atmosphere but rather measures to minimize the adverse effects of possible environmental changes due to human interference with the climate system. Other reasons to discuss adaptation measures are related to the inertia of the climate system including the cumulative nature of anthropogenic emissions; the long lead times required between the political negotiation process, policy actions and the resulting reductions in emissions; and the significant time lags between emission reductions, 
stabilization of atmospheric concentrations and eventual climate stabilization. All told, even in the most ambitious policy scenarios some climate change appears inevitable as a legacy of our past, current and medium-term reliance on fossil fuels and the long response time of the climate system.

In some studies, adaptation is economically more attractive than (massive) mitigation. People and most ecosystems have a natural capacity to adapt to changes in climate. For natural ecosystems, adaptation to environmental changes occurs naturally (e.g., coniferous trees migrate northwards under a warming climate), albeit at very slow rates. Therefore, perhaps more important than absolute changes in climate are the rates by which climate change occurs, whether it occurs gradually, allowing natural ecosystems to adapt, or whether changes are sudden and abrupt. The possibilities of human intervention to facilitate, or to speed up natural adaptation can be considered limited, apart from some generic measures such as the preservation of vegetation migration corridors. This is the principal reason why recent climate impact research identifies natural ecosystems as being the most vulnerable to man-induced climate changes.

The adaptation potential of socioeconomic systems can be considered to be practically unlimited within the range of environmental and climate change anticipated over the next century. After all, human civilization exists under a much wider variation of climate regimes than projected by even the most drastic future climate change scenario. However, adaptation requires the availability of sufficient resources, know-how and time. Appropriate research and development has to be put in place and financed in advance to permit adaptation. Some adaptation measures would simply involve better information and management practices such as early warning systems for extreme climate events, or better information concerning preventive measures to counter greater climate variability. Others would entail potentially significant changes in practices such as different agricultural crops or air and sea routes. These could have disruptive impacts, for example on food markets. Finally, some adaptation may entail considerable costs, such as the protection of low lying coastal areas from sea level rise, relocation of infrastructures, or construction of large enclosed areas for human protection (like superdomes and shopping malls).

Summarized below are examples of different types of adaptation measures for agricultural production. As a first, easy step low-cost adaptation measures include: changes in crop varieties, such as towards more drought resistant species: changes in management practices of agricultural production, for example, different planting dates: and changes in cultivars to completely different crops. A second step would entail substantial adaptations, possibly requiring resources beyond an individual farmer's means. This includes, for instance, additional irrigation, a more intensive application of additional (nitrogen) fertilizer and, ultimately, entire shifts in crop production zones.

The impacts of some of these different types of adaptation measures on world agriculture could be significant. Based on representative, though highly uncertain, regional climate change scenarios, losses in world agricultural output are estimated to range between 0.3 to $4.4 \%$ for an equivalent doubling of carbon dioxide concentrations and assuming intermediate climate sensitivity $[48,49]$. Assuming easy, low-cost adaptations would be available, the adverse impacts are reduced to between a $0.2 \%$ gain in agricultural production to a $3.5 \%$ loss of agricultural output. For the full range of all conceivable adaptation measures, the impacts range from a gain of $0.8 \%$ to a loss of $1.6 \%$ of agricultural GDP. Thus, the available model estimates indicate that, at the global level, 
adverse impacts of climate change on agriculture could be entirely averted through adaptation.

However, this is only true for the global aggregate. Regional differences are persistent and significant. Especially noteworthy are the results that suggest that impacts on agriculture will generally be positive in the northern hemisphere and negative in the developing countries independent of the level of adaptation assumed (see also Section 5.7 below). In any case, impacts are systematically more adverse, the lower adaptation levels are assumed in the crop modelling exercises. Agricultural impacts in the southern hemisphere are much more severe because of the anticipated larger variations in precipitation patterns, the higher dependence of developing economies on agriculture, as well as the possible limitations of implementing adaptation measures due to capital and institutional constraints.

Even if the direct costs of adaptation measures in agriculture might be low, they nevertheless require preparatory action. Appropriate research and development (e.g., in drought resistant crops and changed farming practices) need to be put in place and financed sufficiently in advance.

In contrast, the adaptation measures involving the (re)construction of infrastructures, such as for coastal zone protection or relocation of traffic routes, are extremely capital intensive and provide an additional argument in favour of precautionary mitigation measures. Again, significant differences in the capability to adapt exist between the developed and the developing countries. Ceteris paribus, monetary impacts can be expected to be greater in the industrialized countries because of the much larger capital stock affected. Conversely, adaptation capabilities in terms of technological and institutional know-how and especially capital availability are much greater in the industrialized countries.

This points to the need to consider carefully the differences in impacts, and the mitigation and adaptation potentials, among different world regions and countries as discussed in the next section. It has to be emphasized, however, that significant scientific uncertainties exist with respect to regional climate change impacts and these are unlikely to become resolved in the near-term future. Thus policy-makers have to face these uncertainties especially at the sub-regional and national level.

\subsection{Special circumstances in different world regions}

There are large disparities in the capacity to mitigate and adapt to environmental changes from energy production and use among different regions and countries. Recognizing the common, but differentiated responsibilities, as well as the different social and economic priorities and capabilities to respond to the challenge of global environmental change, the FCCC differentiates among three groups of countries: the industrialized countries of the OECD, the Organization for Economic Cooperation and Development (Annex II countries); the Industrialized countries undergoing a process of economic reform and 'transition to a market economy' (FCCC Annex I countries in addition to Annex II); and finally the remaining (mostly) developing countries. Despite significant differences among individual countries, the following section attempts to summarize some specifics for each of these three regional groupings in terms of impacts of global environmental change and challenges for sustainable energy development. 


\subsubsection{The OCED countries}

Most of the countries in the OECD region are characterized by mature and highly developed economies with high levels of income, energy consumption and energy-related greenhouse gas emissions. As a region they share the highest responsibility for historical and current energy use and greenhouse gas emissions (cf. Section 3.7). They also have the highest near to medium-term emissions reduction potentials, the highest financial and technological mitigation and adaptation capabilities, and generally also the lowest vulnerability to environmental impacts both as a result of their high-income levels and high capabilities for adaptation.

\subsubsection{Countries in transition to a market economy}

The countries in the transition process to a market economy consist primarily of the formally centrally planned economies of Central and Eastern Europe and the former Soviet Union. Although highly industrialized, the transition economies are characterized by a number of unique features.

The transition process is disruptive and is taking longer than initially anticipated. Between 1990 and 1994, the combined economic output of the economies in transition fell by some 40\% [15], an unparalleled drop in peacetime. It is larger than that during the Great Depression of the 1930s. As a consequence, primary energy demand fell by some $25 \%$ over the same time period and energy-related carbon dioxide emissions by some $30 \%$ [21]. Recent scenarios indicate that it may take two to three decades before energy use and emission levels return to their pre-restructuring levels [12,35].

This means that these countries are probably well below any current or near-term commitments for stabilization of emissions as formulated within the FCCC. Additionally, other urgent social and economic priorities, as well as severe capital constraints, have led to low policy priority for any specific and additional mitigation or adaptation measures. A chronic shortage of capital is compounded by significant financing requirements for the replacement of obsolete energy infrastructures and equipment, estimated to amount up to $10 \%$ of the current economic output in the region [50]. At the same time, the process of economic restructuring opens further opportunities for efficiency improvements and structural changes in the energy sector that could reconcile the pressing near-term needs to overcome the effects of the economic depression with the more longer-term objectives of sustainable energy development.

The current (uncertain) estimates of possible impacts of climate change in these regions indicate that they would not all be adverse. For instance, impacts on agriculture would generally be favourable due to the extended growing seasons and higher precipitation [22]. However, significant adverse impacts of climate change are anticipated for most natural ecosystems not managed by man, in particular for boreal forests. Boreal forests are vulnerable because they are more affected by temperature changes than forests in other latitudinal zones and because warming is expected to be high at high latitudes. It is possible that northern tree lines might migrate into regions currently occupied by tundra [22].

Another, scientifically more speculative, impact could be methane releases from permafrost areas, mainly in tundra soils and in the form of methane clathrates. Current estimates of methane releases from melting ground ice in Siberia put emissions between two and ten $\mathrm{TgCH}_{4}$ per year, corresponding to 0.5 to $3 \%$ of current anthropogenic 
emissions [22]. Increasing methane release rates could have a significant additional warming impact because of the large quantities of methane captured in permafrost areas and methane's high radiative forcing. At present, however, information on the depth distribution of methane clathrates is too sparse to enable an assessment of potential methane release rates under a warmer climate.

\subsubsection{Developing countries}

Developing countries face a triple challenge. First, their historical and current contribution to energy-related global environmental stresses is low (Section 3.7) but is expected to increase in the future with the required social and economic development. This, however, will take several decades. According to the IPCC IS92 scenarios [36], the share of developing countries in energy-related carbon dioxide emissions would surpass the $50 \%$ mark between the years 2035 to 2045 and reach shares between $64 \%$ and $71 \%$ of global emissions by the end of the 21 st century. The recent IIASA-WEC scenarios [12,35] explore a wider and more representative range of possible scenarios for developing countries. In the absence of drastic policy measures, the developing countries' share in global energy-related carbon dioxide emissions would surpass $50 \%$ by between 2025 and 2030 and reach between $59 \%$ and $84 \%$ by the end of the 21 st century. Thus, more than five decades would pass before the developing countries would have a similar share in atmospheric concentration increases as the industrialized countries have today; the difference is that they would have more than $80 \%$ of the global population by that time. Thus, historical and current inequalities with respect to emissions and contributions to atmospheric concentration increases will continue to persist for many decades to come.

The second dilemma deals with the much higher vulnerability of developing countries to possible climate changes. Although absolute monetary estimates of damages are affected by a wide range of uncertainty, there is a broad agreement among different studies that damage from climate change accounts for a significantly higher proportion of economic activities in developing countries than in industrialized ones [22]. Even though climate change is generally projected to be much lower in southern than in northern latitudes, these countries have a greater reliance on climate sensitive activities such as agriculture. Currently, agriculture accounts for about $21 \%$ of total economic output in developing countries compared to only $4 \%$ in industrialized countries (OECD and transition economy countries). Larger climate change impacts are also expected in developing countries due to multiple environmental and other stresses including poverty, population growth, pollution, desertification, industrial and infrastructural development, etc.

The third dilemma is that the adaptation possibilities of developing countries are also more limited because of low national incomes that result in low research and development budgets, severe capital scarcities and limited institutional capacities to deal with climate change.

As an illustration, one important category of climate change impacts, namely agricultural production and food availability, is briefly summarized here. It is a recognized objective of the FCCC to assure that food production is not threatened. Impacts on agriculture are twofold. First, are changes in crop yields due to changes in climate variables like temperature and precipitation and possible carbon dioxide fertilization effects. Second, changes in crop production patterns would result in changes in agricultural prices, which would affect food exporters and importers differently. For 
instance, food-importing countries could suffer economic losses due to higher world prices even in scenarios where domestic food production would increase under a changing climate. The scale of impacts is, of course, not only related to the biophysical vulnerability of national agricultural systems, but also to the lack of excess production capacities in most developing countries today.

Table 5.1 summarizes the range of economic impacts on agriculture for an equivalent doubling of carbon dioxide concentration. The range (negative values denote losses, positive denote gains) reflects the uncertainty of regional climate changes as projected by three different climate scenarios. Three different levels of impacts are differentiated. Impacts assuming no carbon dioxide fertilization effects and no adaptation measures, with fertilization and without adaptations, and finally with fertilization and adaptation combined. Obviously, combining fertilization effects and adaptation, damage is reduced significantly at the global as well as the regional level. However, the most significant result is that the estimated damage is systematically greater in developing countries across all scenarios. Damage is highest in the poorest countries of income levels below US\$ 500 per capita. Even in the most optimistic scenario of Table 5.1, losses in agriculture in the poorest developing countries are more than twice as large as in the OECD countries.

Table 5.1 Estimated economic effects of climate change on agriculture in billion US\$

\begin{tabular}{lccc}
\hline $\begin{array}{c}\text { Developing countries } \\
\text { by income level }\end{array}$ & $\begin{array}{c}\text { No Co fertiliz } \\
\text { No adaptation }\end{array}$ & $\begin{array}{c}\mathrm{CO}_{2} \text { fertiliz. } \\
\text { No adaptation }\end{array}$ & $\begin{array}{c}\mathrm{CO}_{2} \text { fertiliz. } \\
+ \text { adaptation }\end{array}$ \\
\hline$<\$ 500 /$ capita & $-57--121$ & $-2--20$ & $\sim 0--15$ \\
$\$ 500-2000 /$ capita & $-26--48$ & $-2--15$ & $\sim 0--11$ \\
$>\$ 2000 /$ capita & $-7--4$ & $-1-\sim 0$ & $\sim 0--1$ \\
REFs $^{\mathrm{a}}$ & $-13--57$ & $+2--11$ & $+2--5$ \\
OECD $^{\mathrm{h}}$ & $-13--18$ & $+3--15$ & $+6--7$ \\
World $^{\text {Sorld }}$ & $-116--248$ & $\pm 0--61$ & $+7--39$ \\
\hline
\end{tabular}

Source: IPCC SAR WG II, [22]

${ }^{a}$ FCCC Annex I countries undergoing the process of transition to a market economy

${ }^{\mathrm{b}}$ FCCC Annex II countries

This illustrates the 'trilemma' of developing countries. These countries bear the lowest responsibility for human interference with the atmosphere but are the most vulnerable to climate changes and they have the lowest capabilities and available resources for adaptation. Consequently, impacts and damages of climate change tend to be largest in the developing world, particularly in the lowest income countries.

\section{Policy instruments to control anthropogenic impacts}

The previous section gave an overview of numerous mitigation and adaptation options for the protection of the atmosphere. Usually these options are discussed from the perspective of possible technological barriers and attractors for their implementation, 
including availability, performance, costs and environmental compatibility. This section on policy instruments focuses on non-technical barriers and impediments, as well as on the non-technical attractors and incentives that have to be dealt with as a prerequisite for the implementation of mitigation and adaptation options. The policy instruments include, among others, market, regulatory and institutional measures.

\subsection{Policies for sustainable energy development}

A generic policy instrument to be mentioned first are measures that raise both public and private awareness, as well as helping to reduce the significant scientific and policy uncertainties involved, especially when dealing with long-term sustainable development criteria and environmental issues. Research, both domestic and through international cooperation, can help to improve knowledge but even improved knowledge does not lead automatically to better policy decisions if the information is confined within a small scientific or technocratic elite. Therefore, public awareness is critical, to promote a favourable social context and acceptance for the implementation of the numerous measures necessary to move societies on environmentally sustainable development pathways.

No single mitigation option is likely to become the unique and universally adopted solution if drastic reductions of emissions from industrial, energy and consumption activities are required. All options must be evaluated in their different regional, national or sectoral contexts and on the basis of full life-cycle analyses. The combination of several mitigation options along improved and new technology chains, plus associated synergies, will be needed to achieve substantial emission reductions. These combinations may be region or sector specific but could also involve generic new technology chains and synergisms such as a stronger reliance on carbon-free energy carriers in the energy sector.

Considerable additional benefits are attached to those options that tackle greenhouse gas emissions and also mitigate other adverse local and regional environmental problems. This point is stressed not merely because of its technical and financial cost-benefit implications but also because it clearly implies a holistic approach to environmental problems that encompasses local and regional as well as potential global concerns. This holistic approach towards simultaneous consideration of social and economic development needs including a comprehensive environmental perspective from the local to the global scale is at the heart of sustainable development.

Likewise, no single policy measure or instrument will be sufficient for the timely development, adoption and diffusion of mitigation options. Pervasive and simultaneous multinational adoption would reduce their differential consequences. Special consideration must be given to policies that foster the adoption of mitigation technologies which enhance economic development without undermining global environmental sustainability. Policy instruments that enable increasing supplies of high quality energy services, growth of per capita income and living standards should receive the highest priority in developing countries. In the industrialized countries with high per capita energy consumption levels and incomes, policies are called upon that reduce emissions without causing a loss of useful energy services. 


\subsection{Policies for energy efficiency and decarbonization}

To achieve these seemingly conflicting objectives of providing better, cleaner, higher quality and more energy services (especially in the developing countries) while avoiding harmful environmental side effects, high priority must be given to efficiency improvements. Such improvements, even using existing plant and equipment, are substantial and can be achieved relatively quickly. The adoption of the currently best available technologies and practices can achieve even more. Section 5 discussed the potential for energy efficiency improvement of some 50\% through the implementation of currently available, best performing technologies worldwide. Considering further technological development, the efficiency improvement potential in the long term would be even more substantial $[22,42]$.

Efficiency improvements are particularly attractive as a target for policy instruments. They generate multiple benefits: lower resource consumption, reduced environmental impacts and lower system costs. Productivity growth of all factor inputs, including energy, is therefore a prerequisite for sustainable economic development. Another class of options that promise the generation of multiple benefits is the decarbonization of the energy system. Decarbonization involves shifts to low-carbon and carbon-free energy sources and carriers: the lower the carbon content of fuels, the lower the environmental impacts are on local air quality, as well as carbon dioxide emissions.

An energy system centred on the energy carriers electricity and hydrogen is virtually emission free at the point of energy end use and can be made emission free also at the point of energy production and conversion. Increased reliance on natural gas (where available), pre or post-conversion carbon removal from fossil sources and carbon-free sources such as renewables and nuclear energy would individually and collectively contribute to the decarbonization of the energy system. The possible implementation instruments for energy efficiency improvements and decarbonization fall into at least four categories: global and international, regional and national, sector specific and technology (chain) specific.

\subsection{Market and non-market policy instruments}

The following generic policy instruments are applicable to the four categories specified above. The broadest division is in market and non-market instruments. Market instruments include taxes, fees, tax exemptions, subsidies (including accelerated depreciation provisions), tradeable permits, 'polluter pays' principles and the internalization of environmental externalities. Non-market instruments include information, advertizements, education, standards and legal and institutional regulations, bans and controls. Most of these market and non-market instruments may work in both directions, removing or establishing barriers, or promoting or hampering progress.

In the short run, the most promising area for the application of market and nonmarket instruments are the energy end-use sectors. The same also applies for the control of chlorofluorocarbons. To a large extent, energy end-use conversion accounts for the highest inefficiencies within the energy system (see Section 5). Because of the huge number of economic agents involved and the difficulty in developing equitable economic incentives, non-market instruments, such as building codes, vehicle standards, or stack emission regulations, have been successfully employed by many countries. Since the 
efficiency improvements in the end-use sector are the key for meeting the sustainable development objective, policy instruments need increasingly to focus on this sector.

Recently, a hybrid of policy instruments encompassing non-market and market elements has gained momentum. Integrated resource planning (IRP) and demand side management (DSM) are instruments imposed on utilities by regulatory institutions with the objective of shifting the focus of utility businesses from selling, for example, just kWhs to selling energy services. Here, utilities have begun to provide economic incentives to their customers for load shifting and replacing inefficient end-use devices. Furthermore, selling energy services instead of energy carriers puts utilities in a better position to market their previously worthless by-products such as waste heat. Consequently, DSM and IRP enhance the prospect for the development of combined heat and power (CHP) and district heat energy systems, furthering substantial efficiency gains.

Greenhouse gas emissions and the possibility of climate change are global phenomena, therefore it is self-evident that international policy implementation is required, quite apart from the competitiveness issue already mentioned. The Framework Convention on Climate Change provides provisions for such measures, e.g., joint implementation schemes. The specific details for implementing these schemes still require careful negotiations, especially the provisions for possible crediting of emission reductions.

The assessment above has indicated that many technological options are available that could promote social and economic development, efficiency improvements and a reduction of environmental impacts. Thus, there is no scarcity in human ingenuity that can be exploited to move onto the path of sustainable development. The main questions concern the policy instruments required to promote, for example, technology capacity building and transfer, efficiency improvements and decarbonization at unprecedented levels. It has to be emphasized that in many instances new policy initiatives can build on existing trends towards more efficient stewardship of resources. There, the task ahead for policy may be less daunting if indeed only a significant acceleration of desirable structural changes in our economies and energy systems is required, as opposed to radical departures from longer-term tendencies.

New institutional arrangements, including both market and non-market instruments need to be introduced at the global level. Instruments for the promotion of sustainable development and for a major reduction of adverse environmental impacts would have to reach beyond voluntary compliance or reliance upon market forces alone. The deal here is not so much one of market failure, i.e., wrong or misleading market signals, but with a situation of market exclusion. In numerous cases, important issues such as externalities have been excluded from any consideration in the market place. Again, it is unlikely that these instruments would be justified or implemented solely to respond to individual environmental challenges, e.g., for the purpose of countering the danger of climate change. Clearly, policy instruments need first of all to be linked to local and regional development priorities such as the improvement of energy services, as well as the improvement of local air quality and other adverse impacts of energy supply and use. Some of these instruments require monitoring the progress of policy implementation and measures to ensure compliance. For example, the creation of new cartels that impede access to environmentally benign technologies must be avoided. 


\subsection{Regional and national policy instruments}

Policy instruments also need to account for regional differences in the levels of human development and the resulting social and development imperatives, levels of resource endowments, and economic and technological vintage structures. For example, implementation instruments in regions with large hydro, wind, biomass or natural gas resources would be different from those in regions with small energy resource endowments. Another example is the development of generic technologies; for example, if deep-ocean carbon dioxide disposal turns out to be environmentally acceptable, it is primarily of interest to some coastal regions. Likewise, the option of carbon dioxide reinjection into depleted gas fields is only feasible in gas-producing regions. Another promising option is a strong reliance on biomass. However, adequate land availability can become a limiting factor. For most renewable sources of energy, including modern biomass, development can also have adverse local environmental impacts which may create other limitations. For example, a stronger reliance on biomass might require the development of 400 to 600 million hectares of sustainable and socially acceptable energy crop plantations [12], harmonized with other agricultural activities such as food production for a global population of, say, ten billion people.

Until the 1980s, regulation was the dominant environmental policy instrument at the national and regional levels. Recently, economic and market-oriented approaches have gained momentum compared with non-market instruments. The application of market instruments at the macroeconomic level is intended to establish undistorted pricing mechanisms and competitiveness. In the energy sector alone, removal of distortionary fuel price subsidies is estimated to lead to substantial efficiency gains of up to $18 \%$ of emissions [6]. Many of these measures may also be needed to establish an equal-level playing field. In economies with emerging new sectors, macroeconomic measures have been applied to provide temporary protection.

\subsection{Policy instruments for adequate financing}

Neither the establishment of level playing fields nor temporary protection can overcome one major economic barrier, especially in the developing countries: namely, the chronic lack of capital. Even if a project has lower life-cycle costs and emissions but higher upfront capital requirements compared with its alternatives, it simply may not attract the necessary financing. In addition, energy and environmental measures compete for limited capital with many other development needs. Developing countries face many urgent problems such as the eradication of poverty, famine, malnutrition, substandard housing, locally contaminated water and air, etc. All compete for scarce resources. However, to meet the rising demand for energy and to assure minimum environmental protection at the local and regional level, capital requirements are expected to increase dramatically in the future. For instance, energy sector financing requirements in the developing countries over the next three decades are estimated to range between US(1990)\$3,000 and 9,000 billion, depending on the growth in energy demand, the structure of energy supply and, most notably, capital availability [51,50]. For comparison, the estimated costs of implementing the Agenda 21 Program are estimated to amount to US\$ 20 billion for the period 1993-2000 [1] to be supplied by grant or concessional terms.

Even in the industrialized countries, where financing for capital-intensive projects is easier to obtain, there are major barriers to efficiency improvements and energy sector 
restructuring and decarbonization at the national level. Often, higher returns can be obtained in areas other than the energy sector. The promotion of flexible, small scale but mass-produced supply and conversion plants and equipment would help resolve some of the financing difficulties by reducing the risk, uncertainty and upfront capital requirements.

\subsection{Policy instruments for enhancing knowledge and skills}

A special problem is the variation of general technology-related knowledge, experience and skills among regions and countries. For example, the developing countries' endowment of know-how and know-why required to induce the development, import and adoption of new technologies often lags behind that of developed countries. There is a need for reliable, impartial information on available technologies, including detailed descriptions. Much of the information about mitigation options and implementation instruments is tailored to the needs and situations in the developed countries and hence of limited use in the developing countries. Informational needs are, however, only the first step. Evaluations and technology assessments of how different options fit into diverse local situations and development needs are important requirements. Hence, local capacity building is essential. Additional non-market barriers include institutional and legal frameworks, procedural requirements, language barriers and the provision of spare parts and maintenance.

Technology appropriateness is also an important issue in this context and must be specifically addressed by both donors and recipients and through joint development. It will be necessary to account for distinct differences in the innovation needs between the industrialized and developing countries. Highly efficient, capital intensive technology options involving minimal labour may be the preferred solution in the industrialized world. For developing countries, the priorities may well be for labour-intensive, low capital and medium efficiency technology to pave the way toward sustainable economic development.

Therefore, complex and capital intensive technologies should first be implemented in the industrialized countries that have both higher research and development and financial resources to cope with the inevitable risks involved in the innovation process. The industrialized countries also need to provide for initial niche markets for new environmentally benign technologies in order that learning curve effects and associated cost reductions are exploited to a maximum before technologies can diffuse to the developing countries. Existing international financial instruments for economic development are seriously out of tune with the innovation needs in the developing countries. Here, policy should encourage and support indigenous innovation impulses and enhanced local capabilities for assessment and adaptation of technologies to best fit to the specific local and national development and environmental priorities.

Provisions of safety and health measures in the workplace have been integrated into the legal and institutional frameworks of modern societies. In short, they are part of the social contract. The implementation of mitigation options at the regional and national levels also requires their inclusion in the social contract. A collective implementation of mitigation policy instruments is required; this is not a question of single technology options. This is a socio-cultural process as well as one of technology and economy. 


\subsection{Sector and technology specific policy instruments}

Policy instruments affecting the entire energy system include emission and energy taxation or regulatory provisions and standards. With the exception of fossil-fuelled electricity generation, the energy supply sector accounts for a smaller share of total energy-related greenhouse gas emissions than the energy end-use sectors. Therefore, carbon taxes levied at the point of emissions would be collected primarily at the level of end-use and thus only indirectly affect the non-electric energy supply sector. A final important generic aspect of regulatory measures is that they must restrict themselves to establishing more comprehensive costing principles by internalizing externalities and focus on performance and environmental standards rather than prescribing particular technologies.

Most innovations spread from centres where the initial adoption occurs. Establishing special ecozones might help catalyze and accelerate sustainable development and the promotion of environmentally friendly technologies. Policy should support the creation of fertile socio-economic conditions. Likewise, broad market instruments are required to create a conducive environment for accelerated innovation and research and development.

The fourth category of implementation instruments is technology-specific and thus very heterogeneous. It involves the promotion and development of individual technologies and their combinations into entire technology chains. The most important instruments in this category involve the removal of non-technical barriers to the innovation and adoption of new technologies and the creation of new attractors for development and diffusion.

In addition to promoting the research and development of the physical aspects of technology, policy instruments should also include paper and software-embodied technology. Manuals, operating procedures and programs are all an integral part of enhancing local skills and know-how. Skills and know-how in turn have to be acquired through formal education, training programs and 'learning by doing'. The human embodiment of technological knowledge is perhaps the most important aspect of this fourth category. Not only does it determine the internal capabilities for appropriating economic and social gains from technologies, but it also determines the capacity for further innovation and the adaptation of new technologies and practices [52]. Capacity building and the development of human resources should be a high priority in any technology development and transfer program, especially at the technology-specific level.

Another critical aspect is the transfer of technology and know-how from the laboratory and development stage to commercialization and subsequent diffusion. Policy instruments include tax exemptions, subsidies with sunset clauses, rewards for technical excellence, end-user subsidies, promotion of integrated resource planning and, where necessary, temporary protective measures. More importantly, the policy instruments should remove barriers to innovation such as protective subsidies for mature technologies and other market imperfections. Research and development policy should make available sufficiently earmarked and stable funding for the development of technologies with long lead times. This condition is of particular importance when the development of a whole set of new technologies is involved. Obviously, related efforts must be greatest where resources are largest, i.e., in the industrialized countries. 
In the case of a transition to completely new production and energy systems and technologies, sometimes called technological leap-frogging, it is important to take account of additional social costs for new infrastructures and supporting systems. For example, a potential barrier might be the need to maintain both the old and the new systems during the transition period leading to additional social costs and perhaps also unsatisfactory services. Considering such and other possible barriers, it is important for the government or some appropriate public body to promote the new systems and remove the hidden barriers until they reach commercialization.

Once a new technology reaches commercialization, a new set of instruments is required to promote flexibility and cost reductions along the learning curve. In the case of modular and flexible technologies, e.g., wind turbines, gas turbines and fuel cells, cost reductions through 'learning by doing' and 'learning by using' can indeed by significant. In other cases, such as the production of large amounts of biomass, the learning curve effects could be more limited, especially in arid areas with little experience of high intensity agriculture.

New problems, however, may emerge with increasing scales of production. Examples in energy supply are particularly numerous as far as adverse environmental impacts are concerned. Each generation of technology has a tendency to solve old problems and yet create new ones [53]. Exceptional care and anticipatory measures will have to be taken if the policy instruments introduced for improving the human condition and for protecting the environment are to avoid the creation of new unanticipated problems and concerns.

\section{Acknowledgements}

We gratefully acknowledge support from the Division of Sustainable Development, United Nations, New York which made this paper possible. We thank Arungu Olende for his encouragement and numerous contributions. We also wish to thank Hans-Holger Rogner for his contributions to Section 5 (policy instruments) and Susan Riley for her editing of the manuscript.

\section{References and Notes}

1 UNCED (United Nations Conference on Environment and Development) (1992) The Global Partnership for Environment and Development A Guide to Agenda 21, 92-1-100481-0, UNCED, Geneva, Switzerland.

2 WHO (World Health Organization) (1994) Urban Air Pollution in Megacities of the World, Blackwell Publishers, Oxford, UK (1994 reprint).

3 Smith, K.R. (1993) 'Fuel combustion, air pollution exposure and health: the situation in developing countries', Annual Review of Energy and the Environment, Vol. 18, pp.529-566.

4 WEC (World Energy Council) (1995a) Local and Regional Energy-Related Environmental Issues, WEC, London, UK.

5 Bolin, B. (1995) 'The possibility of climate change', Special Conference Address, 16th World Energy Congress, Tokyo, Japan.

6 IPCC (Intergovernmental Panel on Climate Change), SAR (Second Assessment Report), (1995) Synthesis of Scientific-technical Information Relevant to Interpreting Article 2 of the Framework Convention on Climate Change, IPCC, Geneva, Switzerland. 
7 UN (United NATIONS) (1987) Protocol on Substances that Deplete the Ozone Layer, 16 September, reprinted in International Legal Materials, Vol. 26, pp.1550ff.

8 Maghrebi, A. (1995) 'Rural energy in developing countries', background paper, 16th World Energy Congress, Tokyo, Japan.

9 UN ECE (United Nations Economic Commission for Europe) (1979) Geneva Convention on Long-range Transboundary Air Pollution 13 November 1979, UN Doc. ECE/HLM.1/R.1, reprinted in International Legal Materials, Vol. 18, pp.1442.ff.

10 FCCC (United Nations Framework Convention on Climate Change) (1992) FCCC Convention Text, UNEP/WMO Information Unit on Climate Change (IUCC), Geneva, Switzerland.

11 Smil, V. (1994) Energy in World History, Westview Press, Boulder, USA.

12 IIASA-WEC (International Institute for Applied systems Analysis and World Energy Council), (1995) Global Energy Perspectives to 2050 and Beyond, WEC, London, UK.

13 Hall, D.O. (1991) 'Biomass energy', Energy Policy, October, pp.711-736.

14 IEA (International Energy Agency), (1994a) Energy Statistics and Balances of OECD and Non-OECD Countries 1971-1992, OECD, Paris, France.

15 World Bank (1995) World Tables, John Hopkins University Press, Baltimore, USA.

16 Nakicenovic, N. (1984) Growth to Limits: Long Waves and the Dynamics of Technology, International Institute for Applied Systems Analysis, Laxenburg, Austria.

17 Maddison, A. (1989) The World Economy in the 20th Century, Development Centre Studies, Organization for Economic Cooperation and Development, OECD, Paris, France.

18 IEA (International Energy Agency), (1994b) Energy in Developing Countries: A Sectorial Analysis, OECD, Paris, France.

19 World Bank (1992) World Development Report 1992: Development and the Environment, Oxford University Press, London, UK.

20 Davis, G. (1990) 'Energy for planet earth', Scientific American, special issue, September, Vol. 263, No. 3., pp.55-62.

21 BP (British Petroleum) (1995 and earlier volumes) BP Statistical Review of World Energy, BP, London, UK.

22 IPCC (Intergovernmental Panel on Climate Change), SAR (Second Assessment Report) WG II (Working Group II), (1995) Draft Document WG II/3 ${ }^{\text {rd }} /$ Doc.3 IPCC, Geneva, Switzerland.

23 Grübler, A. (1993) 'The transportation sector: growing demand and emissions', Pacific and Asian Journal of Energy, Vol. 3, No. 2, pp.179-199.

24 WEC (World Energy Council) (1993) Energy for Tomorrow's World - The Realities, the Real Options and the Agenda for Achievements, Kogan Page, London, UK.

25 Grübler, A. and Nakicenovic, N. (1992) International Burden Sharing in Greenhouse, Gas Reduction, Environment Working Paper No. 55, World Bank Environment Department, Washington, D.C., USA.

26 Fujii, Y. (1990) An Assessment of the Responsibility for the Increase in $\mathrm{CO}_{2}$ Concentration and Inter-Generational Carbon Accounts, WP-90-55, International Institute for Applied Systems Analysis (IIASA), Laxenburg, Austria.

27 Nakicenovic, N. (1987) 'Technological substitution and long waves in the USA', in T. Vasko (ed.), The Long-Wave Debate, pp.76-104, Springer-Verlag, Berlin, Germany.

28 Martin, J.M. (1988) 'L'intensité énergétique de l'activité economique dans les pays industrialisés: les evolutions de très longue periode liverent-elles des enseignements utiles?', Economies et Societés, Vol. 4., pp.9-27.

29 TERI (Tata Energy Research Institute) (1994) TERI Energy Data Directory Yearbook, Pauls Press, New Delhi, India.

30 Reddy, A.K.N. and Goldemberg, J. (1990) 'Energy for the developing world', Scientific American, Special Issue, September, Vol. 263, No. 3, pp.110-118. 
31 Alcamo, J., Bouwman, A., Edmonds, J., Grübler, A., Morita, T. and Sugandhy, A. (1995) 'An evaluation of the IPCC IS92 emission scenarios', Climate Change 1994, pp.247-304, Intergovernmental Panel on Climate Change, Cambridge University Press, Cambridge, UK.

32 Nakicenovic, N. (1993) Decarbonization Doing More With Less, WP-93-076, International Institute for Applied Systems Analysis (IIASA), Laxenburg, Austria.

33 IPCC (Intergovernmental Panel on Climate Change), (1994) Climate Change 1994, Cambridge University Press, Cambridge, UK. (published in 1995).

34 IPCC (Intergovernmental Panel on Climate Change), SAR (Second Assessment Report) WG I (Working Group I), (1995) Scientific Assessment of Climate Change, Cambridge University Press, Cambridge, UK.

35 Nakicenovic, N., Grübler, A. and McDonald, A. (Eds.) (1998) Global Energy Perspectives, Cambridge University Press, Cambridge, UK.

36 Pepper, W., Legett, J., Swart, R. Wasson, J., Edmonds, J. and Mintzer, I. (1992) Emission Scenarios for the IPCC, an Update: Assumptions, Methodology and Results, IPCC, Geneva, Switzerland.

37 The two scenarios developed differ with respect to the role of nuclear energy, but have the same carbon emission levels.

38 Nakicenovic, N., Grübler, A., Inaba, A., Messner, S., Nilsson, S., Nishimura, Y., Rogner, H.H., Schäfer, A., Schrattenholzer, L., Strubegger, M., Swisher, J., Victor, D. and Wilson, D. (1993) 'Long-term strategies for mitigating global warming', Energy, Vol. 18, No. 5, pp.401-609.

39 AIP (American Institute of Physics) (1975) Efficient Use of Energy, Conference Proceedings No. 25, AIP, New York, USA.

40 Olivier, D. and Miall, H. (1983) Energy Efficient Futures: Opening the Solar Option, Earth Resources Research Limited, London, UK.

41 Ayres, R.U. (1988) Energy Inefficiency in the US Economy: A New Case for Conservation, Carnegie-Mellon University, Pittsburgh, USA.

42 Gilli, P.V., Nakicenovic, N. and Kurz, R. (1995) 'First and second law efficiencies of the global and regional energy systems', in Proceedings of the $16^{\text {th }}$ World Energy Congress Division and Rational Energy End-use Technologies, PS/SRD, Vol. 3, No. 1, pp.229-248, WEC, London, UK.

43 Ausubel, J.H., Grübler, A. and Nakicenovic, N. (1988) 'Carbon dioxide emissions in a methane economy', Climate Change, Vol. 12, pp.245-263.

44 It should be noted that under current conditions both nuclear and solar energy options also entail carbon dioxide emissions, simply because fossil energy is required for the fabrication of the materials embodied in plant and equipment and for construction and operation of these energy facilities. Full fuel-cycle analysis is needed to determine the exact amount of emissions of these otherwise genuinely emission free energy sources, but all available analysis suggests significant net emission gains for these options. For biomass, the situation is somewhat different as emissions are inevitably released during combustion. In the case of carbon dioxide these can be neutral if the biomass is harvested on a sustainable basis. Other emissions, e.g., carbon monoxide or methane released during combustion can be reduced through the utilization of appropriate combustion technologies, such as the gasification of biomass in conjunction with combined-cycle gas turbines for electricity generation (IGCC, or integrated gasification combined cycle technology).

45 Lazarus, M.L., Greber, L., Hall, J., Bartels, C., Bernow, S., Hansen, E., Raskin, P. and von Hippel, D. (1993) Towards a Fossil Free Energy Future: The Next Energy Transition, A Technical Analysis for Greenpeace International, Stockholm Environmental Institute, Boston Center, Boston, USA.

46 Nilsson, S. (1993) 'Carbon sequestering potential by global afforestation', Energy - The International Journal, Vol.18, No. 5, pp.506-519. 
47 Nilsson, S. and Schoplfhauser, W. (1995) 'The carbon sequestration potential of a global afforestation program', Climate Change, Vol. 30, pp.267-293.

48 Fischer, G., Frohberg, K., Parry, M.L. and Rosenzweig, C. (1994) 'Climate change and world food supply, demand and trade. Who benefits, who loses?', Global Environmental Change, Vol. 4, No. 1, pp.7-23.

49 Rosenzweig, C. and Parry, M.L. (1994) 'Potential impacts of climate change on world food supply', Nature, Vol. 367, pp.133-138.

50 Nakicenovic, N. and Rogner, H.H. (1995) Global Financing Needs for Long-term Energy Perspectives, WP-95-101, International Institute for Applied Systems Analysis (IIASA), Laxenburg, Austria.

51 WEC (World Energy Council) (1995b) Financing Energy Development: The Challenges and Requirements of Developing Countries, WEC, London, UK.

52 Grübler, A. (1998) Technology and Global change, Cambridge University Press, Cambridge, UK.

53 Gray, P.E. (1989) 'The paradox of technological development', in J.H. Ausubel and H.E. Sladovich (Eds.) Technology and Environment, pp.192-204, National Academy Press, Washington, D.C., USA. 
